Increasing Isoprene Epoxydiol-to-Inorganic Sulfate Aerosol (IEPOX:Sulf inorg $_{\text {) }}$ ) Ratio Results in Extensive Conversion of Inorganic Sulfate to Organosulfur Forms: Implications for Aerosol Physicochemical Properties

Matthieu Riva ${ }^{\dagger, \#, ¥, *}$ Y Yuzhi Chen ${ }^{\dagger, \#}$, Yue Zhang ${ }^{\dagger, \S}$, Ziying Lei ${ }^{\|}$, Nicole E. Olson ${ }^{\perp}$, Hallie C. Boyer ${ }^{\#}$,

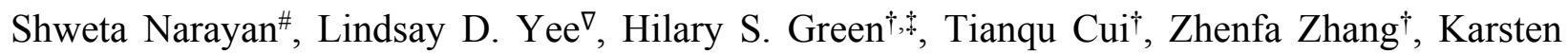
Baumann $^{\circ}$, Mike Fort ${ }^{\circ}$, Eric Edgerton ${ }^{\circ}$, Sri H. Budisulistiorini ${ }^{\dagger}$, , Caitlin A. Rose ${ }^{\dagger}$, Igor O. Ribeiro", Rafael L. e Oliveira", Erickson O. dos $\operatorname{Santos}^{\infty}$, Cristine M. D. Machado ${ }^{\infty}$, Sophie Szopa $\Pi$,

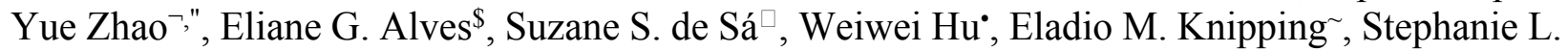
Shaw $\cdots$, Sergio Duvoisin Junior", Rodrigo A. F. de Souzaף, Brett B. Palm;, Jose-Luis Jimenez; Marianne Glasius", Allen H. Goldstein ${ }^{\nabla}$, Havala O. T. Pye ${ }^{\dagger, \mathrm{p}}$, Avram Gold ${ }^{\dagger}$, Barbara J. Turpin ${ }^{\dagger}$, William Vizuete ${ }^{\dagger}$, Scot T. Martin $₫, »$, Joel A. Thornton $\urcorner$, Cari S. Dutcher ${ }^{\sharp}$, Andrew P. Ault" $\perp^{*}$, and Jason D. Surratt $\dagger^{* *}$

\title{
Affiliations:
}

$\dagger$ Department of Environmental Sciences and Engineering, Gillings School of Global Public Health, The University of North Carolina at Chapel Hill, Chapel Hill, NC 27599, USA.

$\S$ Aerodyne Research Inc., Billerica, MA 01821, USA.

" Department of Environmental Health Sciences, University of Michigan, Ann Arbor, MI 48109, USA.

$\perp$ Department of Chemistry, University of Michigan, Ann Arbor, MI 48109, USA.

\# Department of Mechanical Engineering, University of Minnesota-Twin Cities, Minneapolis, MN 55455, USA.

$\nabla$ Department of Environmental Science, Policy, and Management, University of California, Berkeley, CA 94720, USA.

- Atmospheric Research \& Analysis, Inc., Cary, NC 27513, USA.

ฯ Escola Superior de Tecnologia, Universidade do Estado do Amazonas, Manaus, Amazonas, 69050, Brazil.

${ }^{\infty}$ Department of Chemistry, Federal University of Amazonas, Manaus, Amazonas, 69067, Brazil.

П Laboratoire des Sciences du Climat et de l'Environnement, CEA-CNRS-UVSQ-IPSL, 91190, Gif-sur-Yvette, France.

$\neg$ Department of Atmospheric Sciences, University of Washington, Seattle, WA 98195, USA.

$\$$ Environment Dynamics Department, National Institute of Amazonian Research (INPA), Manaus, 69067, Brazil.

$\square$ John A. Paulson School of Engineering and Applied Sciences, Harvard University, Cambridge, MA 02138, USA. 
36 Department of Chemistry and Cooperative Institute for Research in Environmental Sciences, 37 University of Colorado, Boulder, CO 80309, USA.

38 Electric Power Research Institute, Washington, D.C 20005, USA.

$39 \quad \cdots$ Electric Power Research Institute, Palo Alto, CA 94304, USA.

40 "Aarhus University, Dept. of Chemistry and iNANO, 8000 Aarhus C, Denmark.

41 p National Exposure Research Laboratory, US Environmental Protection Agency, Research 42 Triangle Park, NC 27711, USA.

43 " Department of Earth and Planetary Sciences, Harvard University, Cambridge, MA 02138, USA.

This PDF file includes:

Materials and Methods

Figures S1-S10

Tables S1-S7 
Materials and Methods

56 Collection of $\boldsymbol{P M}_{2.5}$ Collection from SE-U.S. $\mathrm{PM}_{2.5}$ samples were collected onto pre-baked $8 \times 10$ in

57 Tissuquartz ${ }^{\mathrm{TM}}$ Filters (Pall Life Sciences) using three high-volume $\mathrm{PM}_{2.5}$ samplers (Tisch Environmental) operated at $1 \mathrm{~m}^{3} \mathrm{~min}^{-1}$ during the 2013 Southern Oxidant and Aerosol Study (SOAS) campaign from 1 June to 15 July 2013 at the CTR, AL ground site. One high-volume sampler collected $\mathrm{PM}_{2.5}$ for $23 \mathrm{~h}(08: 00$ to 07:00 the next day, local time), while the two remaining high-volume samplers followed two cycles. When the sampling schedules were daytime (08:00 - 19:00, local time) and nighttime (20:00 - 07:00, local time), the $\mathrm{PM}_{2.5}$ collected were defined as regular day or night samples, respectively. When atmospheric chemical model simulations predicted a high level of BVOCs, sulfate and $\mathrm{NO}_{\mathrm{x}}{ }^{1}, \mathrm{PM}_{2.5}$ were collected more frequently (collection times were 08:00-11:00, 12:00-15:00, 16:00-19:00, and 20:00-07:00, local time) in order to examine the potential enhancing effect of anthropogenic pollutants on BSOA formation, and are defined as "intensive" samples. Field blanks were also collected weekly by placing pre-baked quartz filters into the 3 non-operating high-volume $\mathrm{PM}_{2.5}$ samplers for $15 \mathrm{~min}$. Filters and field blanks were stored under dark conditions at $-20^{\circ} \mathrm{C}$ until analysis.

Collection of PM P.5 $_{2.5}$ Samples from Central Amazonia (Manaus downtown). $\mathrm{PM}_{2.5}$ samples were collected daily from 18 July through 1 August 2016 on filters similar to those used during the SOAS campaign using a high-volume $\mathrm{PM}_{2.5}$ sampler operated at $1.13 \mathrm{~m}^{3} \mathrm{~min}^{-1}$. The sampling site was located at $6 \mathrm{~m}$ above the ground at the School of Technology of the State University of Amazonas in Manaus, Brazil. The highvolume $\mathrm{PM}_{2.5}$ sampler was flow-calibrated and the filter holder was cleaned with the filter extraction solvent each day before sampling to ensure no chemical carryover between samples. All filters were collected for 24 h. Immediately after collection, the 15 daily $\mathrm{PM}_{2.5}$ filter samples were stored at $-18{ }^{\circ} \mathrm{C}$ under dark conditions until chemical analysis. One field blank was collected during the 15-day campaign by placing a pre-baked quartz filter into the high-volume $\mathrm{PM}_{2.5}$ sampler for $15 \mathrm{~min}$, and then removing and storing it under the same conditions as the field samples. Co-located measurements of total organic and inorganic aerosol mass were not available for Manaus and the contribution of the OS could not be calculated. 
Collection of PM Samples from downwind Manaus. Filters were collected during the Green Ocean Amazon (GoAmazon2014/5) field campaign ${ }^{2}$ during intensive operating period 2 (IOP2) at the T3 site $70 \mathrm{~km}$ downwind of Manaus in August-October of 2014. The prevailing wind direction is from north-east, transporting air masses over the Amazon forest to be mixed with the outflow from Manaus (to the east) before reaching the sampling site. Transport time from city to T3 site was typically $4-5 \mathrm{~h} .{ }^{3}$

Aerosol samples $\left(\mathrm{PM}_{1}\right)$ were collected on quartz fiber filters (101.6 mm diameter, QM-A Quartz, Whatman) using a custom-built sequential filter sampler (Aerosol Dynamics, Inc.). Air was sampled $4 \mathrm{~m}$ above ground level, passed through tubing kept at temperatures below the dew point for trapping excess water, and then through a greaseless cyclone (with a $1 \mu \mathrm{m}$ aerodynamic diameter cut-point), before collection of particles. Filters were pre-treated by baking at $550^{\circ} \mathrm{C}$ for 12 hours. While samples were collected with a 4-hour time resolution, 24-h average data are presented in this study. Field blanks were collected each week by inserting pre-baked filters (same filters used for actual sample collection) into the filter holders for at least a minute, and then removing following the same procedures as it is with field samples. Particle and blank filters were kept frozen $\left(-18^{\circ} \mathrm{C}\right)$ and transported on ice.

\section{Chemical Characterization}

Filter Extraction and Chemical Analysis of OS. Chemical characterization of the $\mathrm{PM}_{2.5}$ samples was performed by UPLC/ESI-HR-Q-TOFMS (6520 Series, Agilent) in the negative ion mode, under operating conditions described in detail elsewhere ${ }^{4,5}$. High-volume quartz filter $37 \mathrm{~mm}$ punches were extracted with $22 \mathrm{~mL}$ of high-purity methanol (LC-MS CHROMASOLV-grade, Sigma-Aldrich) by sonication for $45 \mathrm{~min}$, filtered through 0.2- $\mu \mathrm{m}$ PTFE syringe filters (Pall Life Science, Acrodisc) to remove insoluble particles or quartz filter fibers and blown dry under a gentle $\mathrm{N}_{2}(\mathrm{~g})$ stream at ambient temperature. The dried extracts were reconstituted with $150 \mu \mathrm{L}$ of a 50:50 (v/v) solvent mixture of methanol (LC-MS CHROMASOLVgrade, Sigma-Aldrich) and high-purity water (Milli-Q, 18.2 M). Five $\mu \mathrm{L}$ aliquots were injected onto the UPLC column (Waters ACQUITY UPLC HSS T3 column, $2.1 \times 100 \mathrm{~mm}, 1.8 \mu \mathrm{m}$ particle size) and eluted at a flow rate of $0.3 \mathrm{~mL} \mathrm{~min}^{-1}$ with a solvent mixture of methanol containing $0.1 \%$ acetic acid (LC-MS 
CHROMASOLV-grade, Sigma-Aldrich) and water containing $0.1 \%$ acetic acid (LC-MS CHROMASOLVgrade, Sigma-Aldrich).

Field, lab and blank filters from CTR, were spiked with known amounts of propyl and octyl sulfate (electronic grade, City Chemical LLC) to estimate the extraction efficiency and potential losses throughout the analytical protocol. Neither of these two OS have been identified in atmospheric $\mathrm{PM}_{2.5}$, and thus can be used as internal standards. Recovery was determined to be $89 \pm 14$ (1 std. dev.) \%. To estimate potential losses of MSA, control experiments were performed by analyzing five prebaked filters spiked with a known amount of MSA. Extraction efficiency was above $70 \%$ and was used to correct the quantification of samples. To optimize the quantification of identified BVOC-derived OS, a mixture of IEPOX-OS $\left(\mathrm{C}_{5} \mathrm{H}_{11} \mathrm{O}_{7} \mathrm{~S}^{-}\right)^{1}$, 2-methylglyceric acid sulfate $\left(\mathrm{C}_{4} \mathrm{H}_{7} \mathrm{O}_{7} \mathrm{~S}^{-}\right)^{6}$ and 2-oxopropyl sulfate $\left(\mathrm{C}_{3} \mathrm{H}_{5} \mathrm{O}_{5} \mathrm{~S}^{-}\right)^{7}$ were synthesized in-house as authentic standards. Propyl sulfate $\left(\mathrm{C}_{3} \mathrm{H}_{7} \mathrm{O}_{4} \mathrm{~S}^{-}\right.$; electronic grade, City Chemical LLC) and 3-pinanol-2-hydrogen sulfate $\left(\mathrm{C}_{9} \mathrm{H}_{13} \mathrm{O}_{6} \mathrm{~S}^{-}\right.$; synthesized standard) served as surrogate standards to quantify the remaining OS. Surrogate standards were selected to match as precisely as possible the retention times of the compounds of interest, as summarized in Tables S2-S4. Due to the potential influence of marine air masses at the CTR site, methanesulfonic acid formed from the oxidation of dimethyl sulfide ${ }^{8}$ was also quantified in all $\mathrm{PM}_{2.5}$ samples from CTR using an authentic standard (MSA, Sigma Aldrich, $\geq 99.5 \%$ ) to help with mass closure of total organosulfur compounds.

PILS vials were analyzed by UPLC/ESI-HR-Q-TOFMS operated in negative mode following the analytical procedure described for the ambient filter extracts. PILS vials were analyzed for the data presented in the main text (Figure 1) in order to provide time-resolved information for the conversion of $\mathrm{SO}_{4}{ }^{2-}$ to organosulfur forms.

PILS Operation and Dilution Correction. The aerosols are sampled through an impactor with a 2.5- $\mu \mathrm{m}$ cut-off at a flow rate of $\sim 13 \mathrm{~L} \mathrm{~min}^{-1}$ with a carbon strip denuder (Sunset Labs) upstream of the impactor to remove organic vapor. Cool sample air flow was mixed adiabatically with a steam heated at $98.5-100^{\circ} \mathrm{C}$ in the PILS condensation chamber, which allows aerosol particles to grow sufficiently for collection on a 
quartz impactor plate. Impacted droplets were transferred by a wash-flow at $0.50-0.55 \mathrm{~mL} \mathrm{~min}^{-1}$ into a

131 debubbler and the resulting bubble-free sample liquid was delivered through a tubing with an inline filter

132 into $2 \mathrm{~mL}$ glass vials in a rotating-carousel auto-collector (BMI). Air sampling rate and wash-flow rate were

133 checked and recorded before and after each experiment. Milli-Q water used in the wash-flow was spiked

134 with $25 \mu \mathrm{M}$ of lithium bromide ( $\mathrm{LiBr}$ ) as an internal standard to correct for dilution caused by condensation

135 of water vapor during droplet collection inside the PILS. Ideally the concentrations of lithium bromide in

136 the samples should be identical to that in the wash-flow supply bottle without dilution. When taking into

137 account the addition of water due to condensations, the dilution factor can be calculated on a per sample

138 basis using bromide ion concentration measured by IC as such:

$$
\text { dilution factor }=\frac{\left[\mathrm{Br}^{-}\right]_{\text {wash }}}{\left[\mathrm{Br}^{-}\right]_{\mathrm{i}}}
$$

In this equation, subscript " $i "$ denotes bromide concentration measured in each sample and subscript "wash"

141 denotes the bromide concentration measured for the liquid in the wash-flow supply bottle. Then the

142 correction was made for all SOA tracers in a sample by multiplying the measured tracer concentrations by

143 the dilution factor derived above.

144 Uncertainty Estimates for OS. The use of surrogate standards can lead to significant biases in the OS 145 quantification. The ESI can be highly impacted by the chemical composition of the mobile phase; for example, when increasing the organic content of the eluent, the ionization efficiency increases significantly 9. As presented Table S5, calibration factors were determined for several authentic OS standards to evaluate the impact of the chemical structure as well as the mobile phase composition on the ionization efficiency of the compounds of interest. During the first two minutes of the gradient elution, the mobile phase is composed $100 \%$ water, and therefore effect of solvent composition on ionization efficiency is not expected

151 within this time period. We note that most of the isoprene-derived OS eluted within the first two minutes 152 and sensitivities towards standards eluting within this period are independent of structure. This suggests that uncertainties in quantification using the surrogate standards for OS eluting in this time range are most 
likely small $(<10 \%)$. For the later eluting compounds (e.g. monoterpene-derived OS) the composition of the mobile phase changes and could impact the ionization efficiency. Propyl sulfate and 3-pinanol-2hydrogen sulfate were used as surrogate standards and selected to correspond as precisely as possible to the retention times of the OS identified in the SOA collected during SOAS. Although the sensitivities of propyl and 3-pinanol-2-hydrogen sulfates are of the same order, biases can be expected and might lead to an inaccurate estimation of the concentration of the OS eluting later in the run.

We assume a small uncertainty in the calibration curve itself $(5 \%)$. Uncertainties from the extraction based on the recovery of propyl and octyl sulfates are $15 \%$. In addition to extraction efficiencies and calibration uncertainties, uncertainty related to the volume of air sampled could further contribute to overall uncertainty. In the different campaigns, high-volume samplers were calibrated and the air volumes adjusted based on the meteorological conditions. Therefore, this uncertainty was estimated as 5\%. Overall uncertainty in quantification is estimated to be $\pm 17 \%$.

Characterization of Total Water-Soluble Organosulfur at CTR. Total water-soluble organosulfur compound mass present in SOA collected in the SE-U.S. was determined from the difference between total water-soluble sulfur measured by isotope ratio inductively coupled plasma mass spectrometry (IR-ICP-MS) and sulfate-sulfur measured by ion chromatography (IC) in the same sample aliquot. Sample extractions, sample spiking and standard preparation were performed gravimetrically, using a 5-place readout laboratory balance (Mettler Toledo Model MS205DU). High-volume quartz filter punches $(47 \mathrm{~mm}$, or $37 \mathrm{~mm}$ diameter) were extracted in Thermo-Fisher Nalgene wide mouth lab quality HDPE bottles (1 oz. 02-8935A) with $25 \mathrm{~g}$ distilled deionized water (DIW with $18.2 \pm 0.2 \mathrm{M} \Omega \mathrm{cm}$ resistivity). Each vessel was capped by a polypropylene cap and sonicated without heat for $1 \mathrm{~h}$. After sonication, the sample was allowed to cool, shaken for uniformity, and allowed to equilibrate at $8^{\circ} \mathrm{C}$ overnight.

Each extract was analyzed in triplicate for sulfate via IC using a dual-channel Dionex ICS-3000 ion chromatography system and Dionex AS-1 Autosampler. The IC was calibrated with NIST SRM 3181 (sulfate in water) at concentrations between $10 \mathrm{ngS} \mathrm{g}^{-1}$ and 2,000 $\mathrm{ngS} \mathrm{g}^{-1}$. A gradient profile (5mM-30mM) 
of $\mathrm{KOH}$ was used as eluent for sulfate-S separation (MSA for cations in other channel) with 4 micro-bore IonPac analytical column AS18 (CS16 for cations). Each channel operated a self-regenerating SRS-ULTRA suppressor in external DIW regeneration mode, a CD-1 conductivity detector, and a DP-1/SP-1 gradient pump with built-in degassing. The applied micro-bore system allowed an analyte flow rate of $1 \mathrm{~mL} \mathrm{~min}^{-1}$. DIW was supplied directly to the eluent generator module. The instrument detection limit (IDL) for the sulfate anion expressed in ambient concentrations from field blanks amounts to less than $2 \mathrm{ngS} \mathrm{m}{ }^{-3}$. Average precision determined from triplicate analysis of the samples collected during the study is $0.46 \pm 0.40 \%$. Secondary source standards were used to routinely assess accuracy in terms of recovery, which averages $99.6 \pm 0.4 \%$

Each extract was also analyzed in triplicate for total-S using a Perkin Elmer ELAN DRC-II IRICP-MS operated in Dynamic Reaction Cell (DRC) mode with oxygen reaction gas (UHP 99.999\% $\mathrm{O}_{2}$, Airgas, 4808 Nelson Rd. Morrisville, NC 27560). The IR-ICP-MS was calibrated with NIST SRM 3181 at concentrations between $100 \mathrm{ngS} \mathrm{g}^{-1}$ and $2000 \mathrm{ngS} \mathrm{g}^{-1}$. Standards and sample aliquots were spiked with $\mathrm{Na}_{2}{ }^{33} \mathrm{SO}_{4}$ (Sigma-Aldrich cat. \# 719374) to a final concentration of approximately $1000 \mathrm{ng}^{33} \mathrm{~S} \mathrm{~g}^{-1}$ and then analyzed for ${ }^{32} \mathrm{SO}(48 \mathrm{amu}),{ }^{33} \mathrm{SO}(49 \mathrm{amu})$ and ${ }^{34} \mathrm{SO}(50 \mathrm{amu})$. Total water-soluble $\mathrm{S}$ was calculated as follows:

$$
\text { Total-S }\left[\mathrm{ngS} \mathrm{g}{ }^{-1}\right]=\left({ }^{32} \mathrm{SO} /{ }^{33} \mathrm{SO}\right){ }_{\mathrm{sa}} *\left[{ }^{33} \mathrm{SO}\right]_{\mathrm{sp}} / \mathrm{IR}_{48 / 49}
$$

with ${ }^{32} \mathrm{SO}$ and ${ }^{33} \mathrm{SO}=$ background-corrected counts at $48 \mathrm{amu}$ and $49 \mathrm{amu}$, respectively; sa = sample; $\mathrm{sp}=$ spike concentration $\left[\mathrm{ngS} \mathrm{g}^{-1}\right] ; \mathrm{IR}_{48 / 49}=$ ion intensity ratio for masses 48 and 49 . The instrument detection limit of the IR-ICP-MS can be estimated conservatively at $2 \mathrm{ngS} \mathrm{g}^{-1}$ or $50 \mathrm{ngS}^{-1}$ per sample, translating to less than $2 \mathrm{ngS} \mathrm{m}^{-3}$ atmospheric $\mathrm{PM}_{2.5}$ concentration of total water-soluble S. Average precision for triplicate analysis of samples was $0.35 \pm 0.20 \%$. Recoveries of a secondary sulfate standard $\left(10,000 \mu \mathrm{gS} \mathrm{mL} \mathrm{mL}^{-1}\right.$ 0.5\%, 10M54-5 from HP Standards, Charleston, SC) were $100.3 \pm 0.4 \%$, and recoveries of camphorsulfonic acid (CSA), methanesulfonic acid (MSA) and methionine were $99.9 \pm 0.3 \%, 98.9 \pm 0.3 \%$ and $98.2 \pm 0.2 \%$, respectively (purity of CSA and MSA was 99\% from ACROS Organics via Fisher-Scientific, purity of 
methionine was $>98.5 \%$ from Fisher BioReagents). All recovery checks were run at a $10 \%$ frequency or every 10 samples.

Based on the above results (in particular the $0.16 \%$ uncertainty in the NIST SRM 3181 , the linearity of the IC and IR-ICP-MS calibrations, and the instruments' recoveries of the secondary standards), the approximate $95 \%(\sigma=2)$ uncertainty for the difference between total-S and sulfate-S is $\pm 1.6 \%$. In other words, water-soluble organosulfur compounds are greater than 0 at the $95 \%$ confidence level when total-S via IR-ICP-MS is at least $1.6 \%$ greater than sulfate-S via IC.

\section{Uncertainty Estimates for Water Soluble Sulfate-S by IC and Water Soluble Total-S by ICP-MS.}

\section{$\underline{\text { Sulfate-S via Ion Chromatography }}$}

The mass of sulfate-S in a sample extract is determined as shown in eqn. 1.

$$
\text { Sulfate-S(ng) }=\text { Sulfate-S(ng-g-1 }) * \text { Extract Mass }(g)
$$

The uncertainty (U) in Sulfate-S can then be estimated as shown in eqn. 2

$$
\mathrm{U}_{\text {Sulfate-S }}=\left(\left(\mu_{\text {Sulfate-S }}\right)^{2}+\left(\mu_{\text {Extract Mass }}\right)^{2}\right)^{1 / 2}
$$

Which can be expanded to

$$
\mathrm{U}_{\text {Sulfate-S }}(\%)=100 \% *\left(\left(\mu_{\text {Primary }}\right)^{2}+\left(\mu_{\text {Secondary }}\right)^{2}+\left(\mu_{\text {Rep }}\right)^{2}+\left(\mu_{\text {Dilution }}\right)^{2}+\left(\mu_{\text {Extract Mass }}\right)^{2}\right)^{1 / 2}
$$

Where,

$\boldsymbol{\mu}_{\text {Primary }}=$ relative uncertainty in the primary sulfate standard $($ NIST SRM 3181$)=0.0016$, from NIST certificate.

$\boldsymbol{\mu}_{\text {Secondary }}=$ relative recovery of the secondary sulfate standard $=0.0039$, measured.

$\boldsymbol{\mu}_{\mathrm{Rep}}=$ relative standard deviation of sample replicates $=0.0046$, measured.

$\boldsymbol{\mu}_{\text {Dilution }}=$ relative standard deviation of primary standard diluent mass $=0.0003$, based on balance uncertainty of $+/-10 \mathrm{mg}$ for $30 \mathrm{~g}$ standard.

$\boldsymbol{\mu}_{\text {Extract Mass }}=$ relative standard deviation of extract mass $=0.0003$, based on balance uncertainty of +/- $10 \mathrm{mg}$ for $30 \mathrm{~g}$ sample extract.

Estimated $\mathrm{U}_{\text {Sulfate-S }}=0.60 \%$ 
230 The mass of Total-S in a sample extract is determined as shown in eqn. 4.

253 Where,

Where,

$$
\begin{aligned}
& \text { Total-S(ng) = Total-S(ng-g-1 }) * \operatorname{Extract} \operatorname{Mass}(\mathrm{g}) \text { (4) } \\
& =\left({ }^{32} \mathrm{SO} /{ }^{33} \mathrm{SO}\right)_{\mathrm{sa}} *\left[{ }^{33} \mathrm{~S}\right]_{\mathrm{sp}} / \mathrm{IR}_{48 / 49} * \text { Extract Mass }(5)
\end{aligned}
$$

$$
\left({ }^{32} \mathrm{SO} /{ }^{33} \mathrm{SO}\right)_{\mathrm{sa}}=\text { ratio of background-corrected counts at } 48 \text { amu and } 49 \mathrm{amu}
$$$$
\left[{ }^{33} \mathrm{~S}\right]_{\mathrm{sp}}=\text { concentration of }{ }^{33} \mathrm{~S} \text { in the spiked sample }
$$

$$
\mathrm{IR}_{48 / 49}=\text { ion ratio for } 48 \mathrm{amu} \text { and } 49 \mathrm{amu} \text { (counts per } n g-\mathrm{g}^{-1} / \text { counts per } n g-\mathrm{g}^{-1} \text { ) }
$$

$\mathrm{IR}_{48 / 49}$ is determined by spiking approximately $1000 \mathrm{ngS}-\mathrm{g}^{-1}$ of $\mathrm{K}_{2}{ }^{33} \mathrm{SO}_{4}$ into solutions of NIST SRM 3181

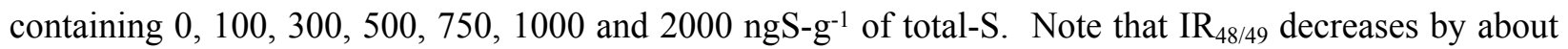
$1 \%$ over the observed calibration range, due to the presence of naturally-occurring ${ }^{33} \mathrm{~S}$ in SRM 3181 . To partially compensate for decreasing IR, we bin IRs over successive pairs of calibration standards and use the one that brackets an individual sample concentration to calculate Total-S. For example, if the initial

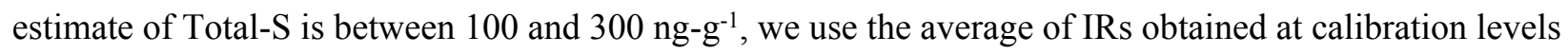

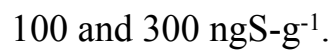

The overall procedure assumes that the isotopic composition of SRM 3181 is at least roughly equal to that of naturally-occurring sulfur (and, by inference, ambient samples). To confirm this, we asked a thirdparty laboratory to measure $\mathrm{del}^{34} \mathrm{~S}$ on a subsample of SRM 3181. Results showed $\operatorname{del}^{34} \mathrm{~S}$ of +17 parts per thousand, relative to Canyon Diablo Troilite. The del ${ }^{33} \mathrm{~S}$ should be similar to this, based on mass dependent fractionation $\left(0.5\right.$ times del $\left.{ }^{34} \mathrm{~S}\right)$ plus mass independent fractionation ( 0.6 to 1.0 times $\left.\mathrm{del}^{34} \mathrm{~S}\right)$. The impact of these enrichments is negligible, so we did not adjust SRM 3181 concentrations.

Based on the above, $\mathrm{U}_{\text {Total-S }}$ can be estimated as shown in eqn. 6

$$
\begin{aligned}
& \mathrm{U}_{\text {Total-S }}=100 \% *\left(\left(\mu_{\mathrm{CP}-3181}\right)^{2}+\left(\mu_{\mathrm{IP}-33 \mathrm{~S}}\right)^{2}+\left(\mu_{\mathrm{CP} 33 \mathrm{~S}}\right)^{2}+\left(\mu_{\mathrm{IR}}\right)^{2}+\left(\mu_{32 \mathrm{SO} / 33 \mathrm{SO}}\right)^{2}+\left(\mu_{\text {Secondary }}\right)^{2}+\right. \\
& \left.\left(\mu_{\text {Dilution }}\right)^{2}+\left(\mu_{\text {Spike Mass }}\right)^{2}+\left(\mu_{\text {Extract Mass }}\right)^{2}\right)^{1 / 2}
\end{aligned}
$$

$$
\boldsymbol{\mu}_{\mathbf{C P}-\mathbf{3 1 8 1}}=\text { chemical purity of SRM } 3181=0.004 \text { (manufacturer's certificate). }
$$


$\boldsymbol{\mu}_{\mathrm{IP}-33 \mathrm{~S}}=$ isotopic purity of ${ }^{33} \mathrm{~S}$ standard $=0.0013$ (ARA analysis of high concentration solutions). $\boldsymbol{\mu}_{\mathrm{CP33S}}=$ chemical purity of ${ }^{33} \mathrm{~S}$ standard, pooled relative standard deviation of for sulfate, CSA, MSA and methionine $=0.006$.

$\boldsymbol{\mu}_{\mathrm{IR}}=$ relative standard deviation of IR across full calibration curve $=0.0034$.

$\boldsymbol{\mu}_{32 \mathrm{SO} / 33 \mathrm{SO}}=$ relative standard deviation of triplicate sample analyses $=0.0035$.

$\boldsymbol{\mu}_{\text {Secondary }}=$ relative standard deviation of secondary $\mathrm{SO}_{4}$ standard recoveries $=0.0042$.

$\boldsymbol{\mu}_{\text {Dilution }}=$ relative standard deviation of primary standard diluent mass $=0.0003$, based on balance uncertainty of $+/-10 \mathrm{mg}$ for $30 \mathrm{~g}$ standard.

$\boldsymbol{\mu}_{\text {Spike Mass }}=$ relative standard deviation of primary standard diluent mass $=0.0016$, based on balance uncertainty of $+/-10 \mathrm{mg}$ and $6 \mathrm{~g}$ sample aliquot.

$\boldsymbol{\mu}_{\text {Extract Mass }}=$ relative standard deviation of extract mass $=0.0003$, based on balance uncertainty of +/- $10 \mathrm{mg}$ for $30 \mathrm{~g}$ sample extract.

Estimated $\mathrm{U}_{\text {Total-S }}=0.99 \%$.

Combining $\mathrm{U}_{\text {Sulfate-s }}$ and $\mathrm{U}_{\text {Total-s }}$ and applying a coverage factor $(\mathrm{k})$ of 2 yields an estimated uncertainty for the difference between Total-S and Sulfate-S of $2.3 \%$, with a confidence interval $\geq 75 \%$.

Microscopy Imaging. A 3-stage microanalysis particle sampler (MPS-3, California Measurements, Inc.) with size cuts of 5.0, 2.5, and $0.4 \mu \mathrm{m}$ was operated at $2.1 \mathrm{~L} \mathrm{~min}^{-1}$. Particles were impacted onto carbontype-b Formvar-coated copper transmission electron microscopy (TEM) grids and silicon wafer substrates (Ted Pella, Inc.). Samples were stored in sealed plastic vials at room temperature prior to analysis. Particles collected onto silicon substrates were imaged in $5 \times 5 \mu \mathrm{m}$ regions by an AFM (Anasys Instruments) in tapping mode with $75 \pm 15 \mathrm{kHz}$ resonant frequency and 1-7 $\mathrm{N} \mathrm{m}^{-1}$ spring constant at ambient laboratory temperature $\left(\sim 23{ }^{\circ} \mathrm{C}\right)$, pressure, and $\mathrm{RH}(\sim 36 \%)$. SEM analysis of particles collected onto TEM grids was performed by a FEI Helios 650 Nanolab-Dualbeam electron microscope equipped with a high angle annular dark field (HAADF) detector operated at an accelerating voltage of $10.0 \mathrm{kV}$ and a current of $0.80 \mathrm{nA}$ under vacuum conditions $\left(10^{-3}\right.$ to $\left.10^{-5} \mathrm{~Pa}\right)$. SEM particles were analyzed orthogonal to the beam on TEM grids and at a 55-degree angle (tilted) on the silicon wafer. 

also conducted with SOA samples (2-MT and IEPOX-OS) extracted from filters using methanol as the solvent. It is observed (Figures S2A and S2B) that methanol itself causes a significant decrease in interfacial tension compared to pure water. Furthermore, similar to the 2-MT and IEPOX-OS samples in water, interfacial tension depression was observed with methanol as the solvent for SOA samples. Figure S2A shows the slight decrease in interfacial tension measured with 2-MT in methanol, compared to the solvent (methanol in water). At $50 \mathrm{mg} / \mathrm{mL}$ SOA, IEPOX-OS shows a larger depression in interfacial tension compared to 2-MT (Figure S2B). Finally, when AS is added, significant salting out is observed at $25 \mathrm{mg} / \mathrm{mL}$ of IEPOX-OS (Figure S2B).

Isotherm Model for Interfacial Tensions. A surface tension model using adsorption isotherms and based on statistical mechanics was applied to the microfluidic measurements for the 2-MT (Figure S9) and IEPOX-OS compounds (Figure 4A). Traditionally, Langmuir-like isotherm models are applied to surface active organics, such as two parameter Szyszkowski equation (see eq. 1 in Schweir et al. ${ }^{10}$ for an example). In the model applied here, unique features of the surface partition function are that the adsorption sites are solvent molecules (waters) and that solutes can occupy a non-integer number of sites using a multifactorial skip, implicitly accounting for the size of the solute. The model expression for binary solutions is $\sigma=\sigma_{\mathrm{w}}-$ $\mathrm{kT} / \mathrm{rS} \operatorname{Ln}\left(1+\mathrm{Ka}_{\mathrm{s}}\right)$, where $r$ is the surface partition function multifactorial skip, $K$ is a solute bulk energy term, $\sigma_{w}$ is the surface tension of pure water, $S_{w}$ is the area of adsorption sites (the projected area of one water molecule, $0.1 \mathrm{~nm}^{2}$. The expression was normalized by the interfacial tension value of pure water from biphasic microfluidic tensiometry and subsequently applied to the measurements of 2-MT and IEPOX OS water. The solute bulk energy term $(K)$ follows the expected size-dependence for each compound: $K=$ 47.35 for 2-MT $\left(\mathrm{M}_{\mathrm{w}}=136 \mathrm{~g} \mathrm{~mol}^{-1}\right)$ and $K=66.00$ for IEPOX-OS $\left(\mathrm{M}_{\mathrm{w}}=215 \mathrm{~g} \mathrm{~mol}^{-1}\right)$. The surface function variable ( $r$ ) also follows the size-dependence, as $r=71.38$ for IEPOX-OS and $r=27.24$ for 2-MT. For the salty solutions, the concentrations, or solute activities, were modified using Setschenow constant $\left(\mathrm{K}_{\mathrm{s}} \mathrm{C}_{\text {salt }}=\right.$ $\log \left(\gamma_{\gamma_{0}}\right)$, where $\gamma_{\text {is }}$ the organic activity in salty water and $\gamma_{0}$ is the organic activity in pure water. Thus, 
$\mathrm{K}_{\mathrm{s}}$ shows enhancement or depletion of organic surface partitioning due to the presence of salt in solution. An important assumption is that in pure water, the organic activity coefficient is unity at concentrations less than $1.0 \mathrm{~mol} / \mathrm{L}$. Incorporating the Setschenow equation into the surface tension equation results in $\sigma=\sigma_{\mathrm{w}}-$ $\mathrm{kT} / \mathrm{rS} \operatorname{Ln}\left(1+\mathrm{Ka}_{\mathrm{s}} * 10^{\mathrm{K}_{\mathrm{s}} \mathrm{c}_{\mathrm{s}} \mathrm{lt}}\right)$. If parameters $K$ and $r$ are optimized from the pure water case and interfacial tension is known for the same concentration of organic in both pure water and salty water, then $\mathrm{K}_{\mathrm{s}}$ is the single parameter. Recently, Toivola et al. ${ }^{11}$ performed quantum chemistry computations of Ks for 2-MT in 0.009 and 0.09 mole fraction of $\mathrm{AS}$ and found $\mathrm{Ks}=0.568 \mathrm{~kg}-\mathrm{mol}-1$ and $\mathrm{Ks}=0.866 \mathrm{~kg}-\mathrm{mol}-1$, respectively. Our AS mole fraction is 0.03 and we find $\mathrm{Ks}=0.299 \mathrm{~kg}-\mathrm{mol}-1$ for 2-MT.

Flow Tube Experiments. The flow tube, CIMS, as well as aerosol and gas phase IEPOX generation have been described in detail elsewhere. ${ }^{12}$ Briefly, the flow tube consists of a 6 x $90 \mathrm{~cm}$ Pyrex cylinder having inner walls coated with halocarbon wax to reduce the wall loss of IEPOX gas. ABS aerosol particles were generated using a constant output atomizer (TSI Inc., Model 3076) from dilute solutions ( $0.1 \mathrm{wt} \%)$. The atomizer output was diluted and conditioned to about $38 \% \mathrm{RH}$ by mixing with a $3 \mathrm{~L} \mathrm{~min}^{-1}$ flow of humidified ultrahigh purity (UHP) $\mathrm{N}_{2}$ before entering the flow tube. The IEPOX vapor was generated by a flow of 30 standard cubic centimeters per minute (sccm) of UHP $\mathrm{N}_{2}$ over $\sim 200 \mu 1$ trans- $\beta$-IEPOX solution in ethyl acetate in a glass bulb at room temperature $\left(\sim 23^{\circ} \mathrm{C}\right)$, and was injected into the flow tube via a movable injector downstream of the aerosol inlet. A constant $2 \mathrm{~L} \mathrm{~min}^{-1}$ flow of conditioned aerosol was drawn through the flow tube by the CIMS and a scanning mobility particle sizer (SMPS) connected to the flow tube exit, which provided real-time measurements of the gas-phase IEPOX concentration and aerosol surface area (Sa), respectively. The IEPOX injector was moved in $10 \mathrm{~cm}$ increments from the bottom (10 $\mathrm{cm}$ above the flow exit) to the top ( $70 \mathrm{~cm}$ above the flow exit) of the flow tube to vary the reaction time between IEPOX and aerosol particles. The decay of gas phase IEPOX signal versus injector position (reaction time) in the presence and absence of aerosol particles was measured to derive $k_{o b s}$ and $k_{\text {wall, }}$ respectively, and the pseudo-first-order reaction rate constant $k_{\text {het }}$ for IEPOX uptake onto particles was determined as $k_{h e t}=k_{o b s}-k_{\text {wall }}$ The IEPOX signals measured at every three adjacent injector positions (i.e., 
$10-30,20-40,30-50,40-60,50-70 \mathrm{~cm}$ ), which correspond to different average reaction times, were used to

332 determine the $k_{\text {het }}$ and then $\gamma_{\mathrm{IEPOX}}$ as a function of reaction time. $\gamma_{\mathrm{IEPOX}}$ is calculated by the following 333 equation:

$$
\gamma_{I E P O X}=\frac{4 k_{h e t}}{S_{\mathrm{a}} \omega}
$$

where $\omega$ is the mean molecular speed of trans- $\beta$-IEPOX under the experimental condition $\left(\omega_{\mathrm{IEPOX}}=231 \mathrm{~m}\right.$ $\left.\mathrm{S}^{-1}\right) \cdot{ }^{13,14}$

Viscosity Calculation of IEPOX-derived OS and water mixtures. The improved parameterization by Derieux et al. ${ }^{15}$ was designed to predict, Tg of pure compounds containing carbon, hydrogen and oxygen using the number of carbon $(\mathrm{nC})$, hydrogen $(\mathrm{nH})$, and oxygen $(\mathrm{nO})$, as shown in eqn. 8 .

$$
T_{g, \text { org }}=\frac{n_{C}^{0}+\ln \left(n_{C}\right)}{b_{C}}+\ln \left(n_{H}\right) b_{H}+\ln \left(n_{C}\right) \ln \left(n_{H}\right) b_{C H}+\ln \left(n_{O}\right) b_{O}+\ln \left(n_{C}\right) \ln \left(n_{O}\right) b_{C O}
$$

where $n_{C}^{0}$ is the reference carbon number, $b_{C}, b_{H}$ and $b_{O}$ represent the contribution of each atom to $T_{g}$, and $b_{C H}$ and $b_{C O}$ are coefficients that reflect contributions from carbon-hydrogen and carbon-oxygen bonds, respectively. The values for these parameters used in this study were derived by DeRieux et al. ${ }^{15}$ based on empirical fit and are shown in Table S6. However, the sulfur atom was not considered in the method. For a conservative estimation of $T_{g}$ of IEPOX-OS, the sulfur atom is assumed to have the same effect on $T_{g}$ as an oxygen atom. The $T_{g}$ of IEPOX-OS, IEPOX-OS dimer and trimer are estimated to be $298 \mathrm{~K}, 333 \mathrm{~K}$, and $360 \mathrm{~K}$, respectively. The glass transition temperature of the sum of uncharacterized IEPOX-derived OS is assumed to be the same as the IEPOX-OS dimers to give a more conservative estimation. Taking into account the mass fraction of each OS compound based on the chemical data shown in Figure 1B (Amazon ratio) at $120 \mathrm{~min}$, the $T_{g}$ of the IEPOX-OS mixtures is calculated using the Gordon-Taylor equation based on the estimation of hygroscopicity, and the Gordon-Taylor constant among orgnaic compounds $\left(k_{G T}=1\right)$ as well as the Gordon-Taylor constant between water and the organics $\left(k_{G T}=12.5\right)$, as shown in eqn. 9. The upper hygroscospity value of 0.15 is based on the upper hygroscopicity range of organic compounds. 
Gordon-Tayler constants between IEPOX-OS mixtures and water, and IEPOX-OS mixtures themselves are assumed to be 2.5 , and 1 , respectively based on previous studies. ${ }^{15-18}$

$$
T_{g, \operatorname{mix}}(R H)=\frac{\left(1-w_{\text {org }}(R H)\right) T_{g, c}+\frac{1}{k_{G T}} \sum_{i=1}^{n} w_{i, o r g}(R H) T_{g, i, o r g}}{\left(1-w_{\text {org }}(R H)\right)+\frac{1}{k_{G T}} \sum_{i=1}^{n} w_{i, o r g}(R H)}
$$

where $\mathrm{n}$ denotes total number of organic compounds in the mixture and i denotes each organic compound; w_(i,org) is the mass fraction of organic compound $i$. The dependency of viscosity on RH is reflected in mass fraction terms as variable $\mathrm{RH}$ changes the amount of water taken up by the SOA, which can be calculated using hygroscopicity $(\kappa) .{ }^{15,19}$

\section{Thermodynamic Model of Aerosol pH.}

The $\mathrm{pH}$ of aerosol particles during the reaction processes are calcualted using a termodynamic model employing two methods. The first method uses measured $\mathrm{SO}_{4}{ }^{2-}$ concentration as well as the $\mathrm{NH}_{4}{ }^{+}$ concentration at the beginning of the experiment as the input values. The IEPOX-OS concentration was not considered. The second method takes into consideration all cations and anions in the aqueous aerosol particle.

The acidity model considers the acid disassociation of $\mathrm{NH}_{4} \mathrm{HSO}_{4}$ and $\mathrm{H}_{2} \mathrm{O}$. For scenario 1 , the IEPOX-OSs were not considered. For scenario 2, IEPOX-OSs, including IEPOX-OS, IEPOX-OS dimer, and IEPOX-OS trimer, were taken into consideration in the model. The acid disassociation reactions of the above compounds are described below:

$$
\begin{gathered}
\mathrm{NH}_{4}+\mathrm{H}_{2} \mathrm{O} \rightleftharpoons \mathrm{NH}_{3} \cdot \mathrm{H}_{2} \mathrm{O}+\mathrm{H}^{+} \\
\mathrm{HSO}_{4}^{-} \rightleftharpoons \mathrm{H}^{+}+\mathrm{SO}_{4}^{2-} \\
\mathrm{H}_{2} \mathrm{O} \rightleftharpoons \mathrm{H}^{+}+\mathrm{OH}^{-} \\
\text {IEPOX }-\mathrm{OS} \rightleftharpoons \mathrm{IEPOX}-\mathrm{OS}^{-}+\mathrm{H}^{+} \\
\text {IEPOX }-\mathrm{OS}_{\text {dimer }} \rightleftharpoons \text { IEPOX }-\mathrm{OS}_{\text {dimer }}^{-}+\mathrm{H}^{+} \\
\text {IEPOX }-\mathrm{OS}_{\text {trimer }} \rightleftharpoons \text { IEPOX }-\mathrm{OS}_{\text {trimer }}^{-}+\mathrm{H}^{+}
\end{gathered}
$$


378 The acid disassociation equilibrium equations for (10)-(15) were constructed, with $\mathrm{pK}_{\mathrm{a}}$ values for Eqs.

$379(7,8,9)$ were obtained from the literature. The $\mathrm{pK}_{\mathrm{a}}$ values for Eqs. (13)-(15) were assumed to be $\sim 2$, with a

380 range of 0-4. The proton balance equation together with the mass balance equations for $\mathrm{NH}_{4}^{+}, \mathrm{HSO}_{4}^{-}, \mathrm{H}^{+}$, $381 \mathrm{SO}_{4}{ }^{2-}$, and IEPOX-OS monomer, dimer, and trimers were built to solve the $\mathrm{H}^{+}$ion concentration. The gas382 particle balance of the $\mathrm{NH}_{3}, \mathrm{NH}_{4}{ }^{+}$was considered with a Henry's law constant of $0.0161 \mathrm{~atm} \mathrm{M}^{-1}$. A growth 383 factor of 1.3 was used to calculate the liquid water content of the particles. The activity coefficients for all 384 ions were assumed to be 1. 

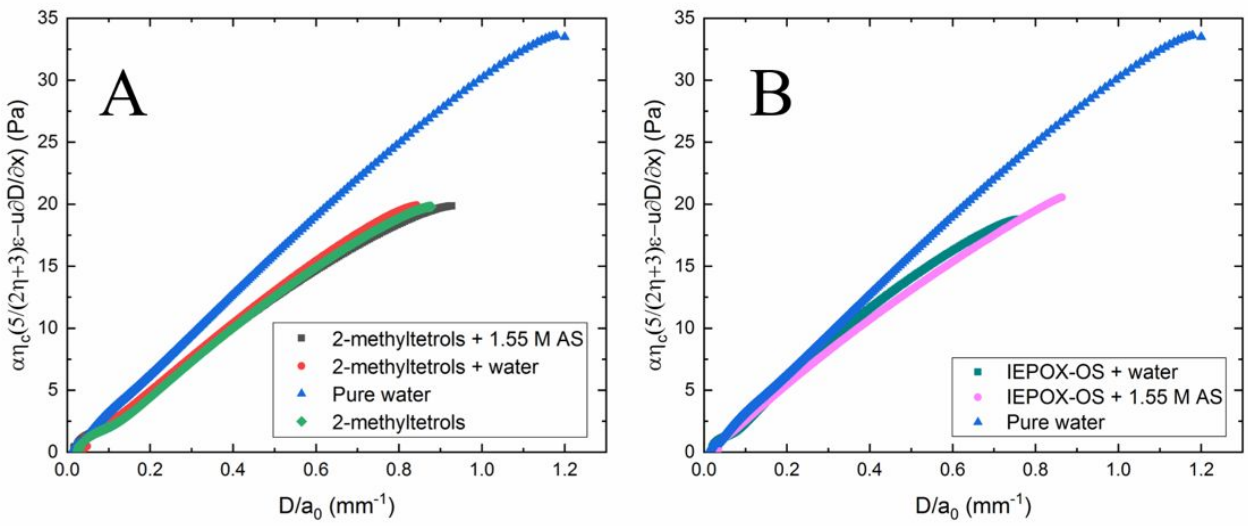

387 Figure S1. Representative Taylor plots (single droplet) for (A) 2-MT and (B) IEPOX-OS samples (in 388 water). The slope of the linear portion of the curves is equal to the interfacial tension. Interfacial tensions 389 reported in this work are the median values of interfacial tension (over all droplets) for any given system.

390 Normalized data points are shown in Figures 4A and S3. 

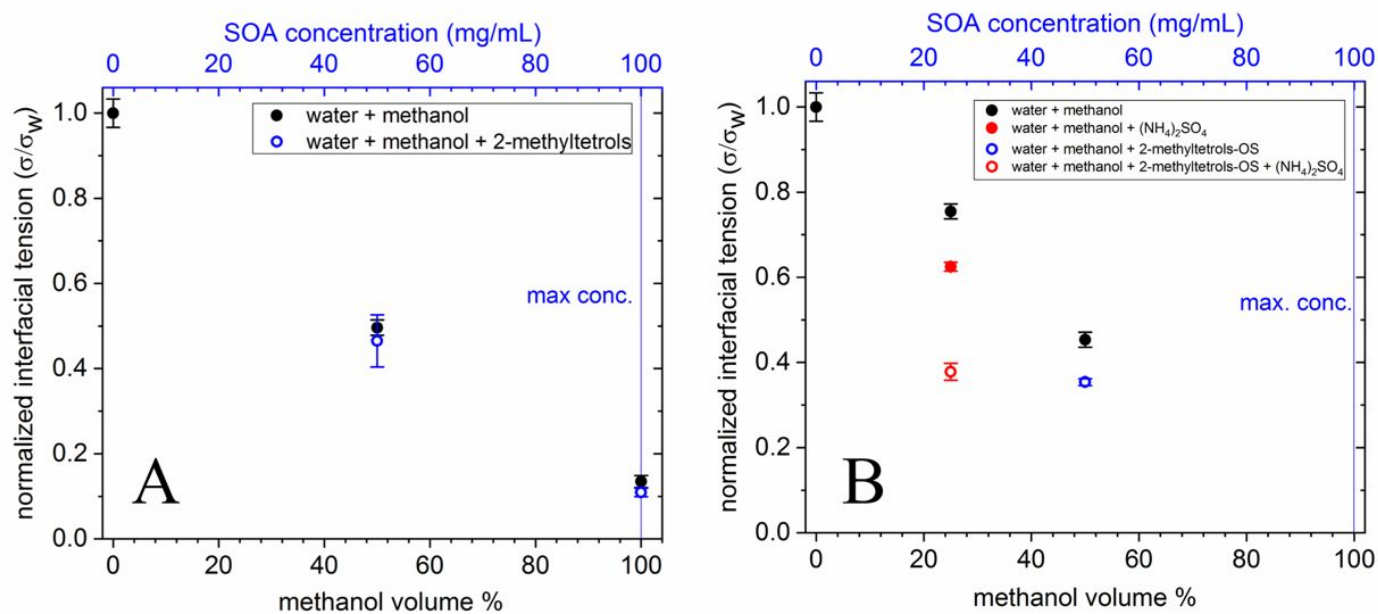

393 Figure S2. Interfacial tensions measured with microfluidics, for (A) 2-MT and (B) IEPOX-OS, with 394 methanol as the solvent. For 2-MT, approximately $300 \mu \mathrm{L}$ of sample was used to prepare a $50 \mathrm{mg} / \mathrm{mL}$ 395 sample of 2-MT in water, approximately $300 \mu \mathrm{L}$ was used to prepare a $50 \mathrm{mg} / \mathrm{mL}$ solution with AS and the 396 remaining was used for the $100 \mathrm{mg} / \mathrm{mL}$ experiment. Similarly, two different solutions were prepared for 397 the IEPOX-OS measurements (with and without AS) at $50 \mathrm{mg} / \mathrm{mL}$. 


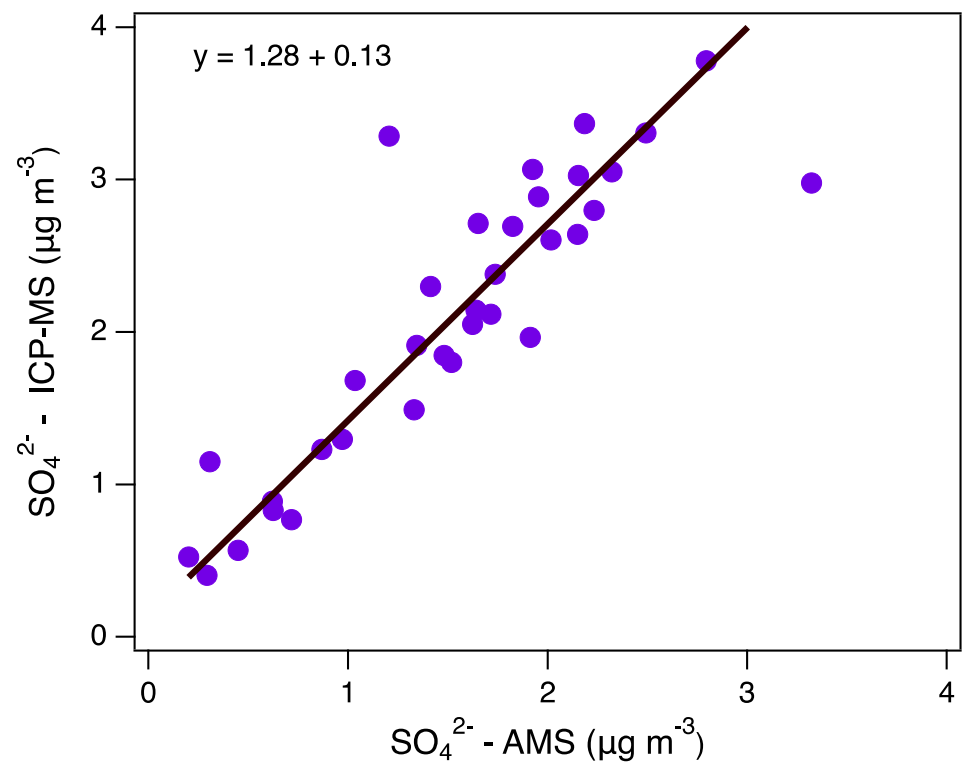

400 Figure S3. Comparison between aerosol sulfate measured by ICP-MS and AMS during the campaign in 401 the SE-U.S.

402 
A
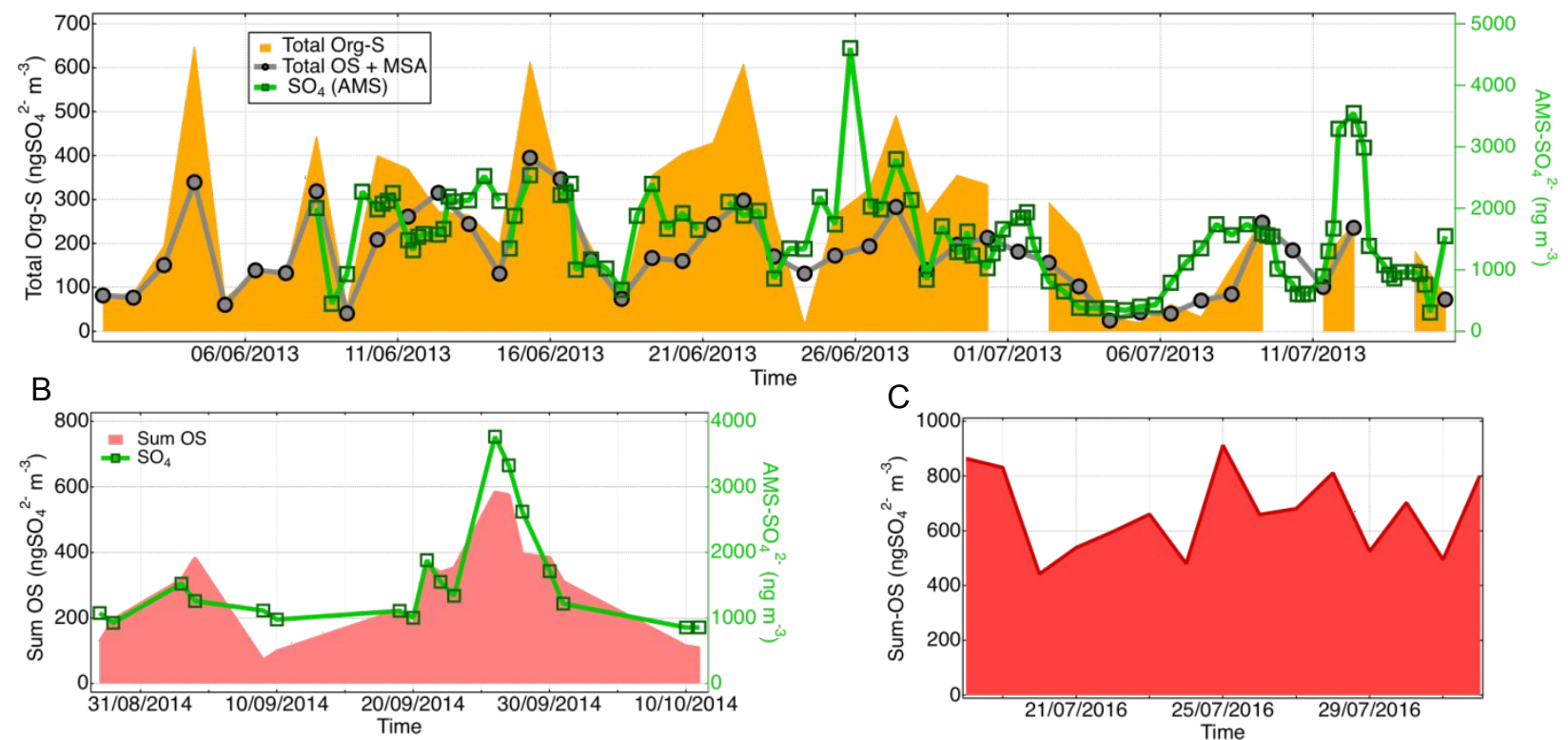

C

Figure S4. (A) Time-series of the sum of identified OS + MSA and total organosulfur compounds (Org-S)

406 quantified by UPLC/ESI-HR-Q-TOFMS and IR-ICP-MS, respectively, in the $\mathrm{PM}_{2.5}$ samples collected 407 during the 2013 SOAS campaign. (B) and (C) present the concentrations of the sum of OS + MSA 408 quantified in downwind Manaus and Manaus, respectively. 
A

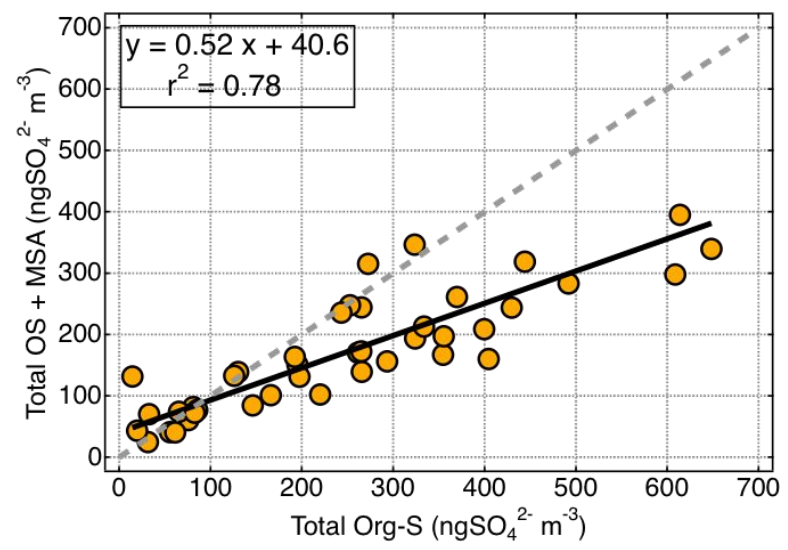

B

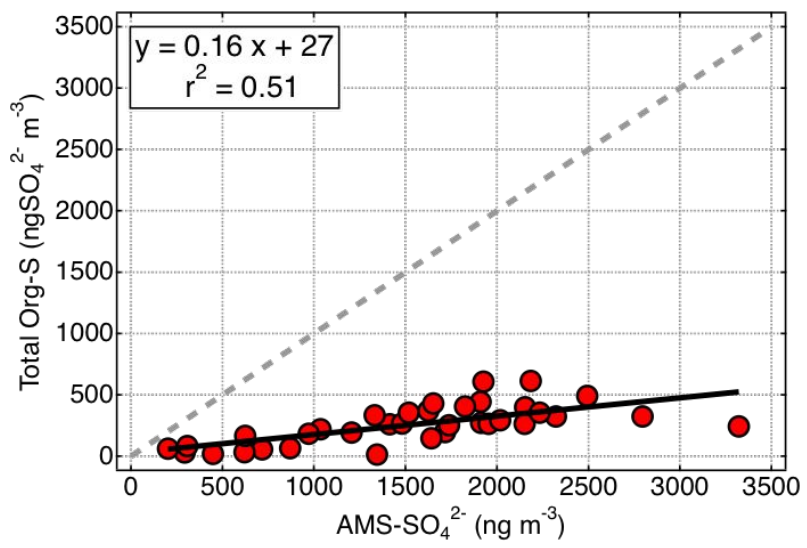

Figure S5. (A) Correlation between the sum of OS + MSA (y-axis) and Org-S (x-axis). This correlation

411 suggests significant unidentified sources of organosulfur compounds in SOA sampled in the SE-U.S. (B)

412 Correlation between Org-S (y-axis) and the mass of sulfate measured by the AMS in SE-US. Dashed grey

413 lines correspond to 1:1 line. OS + MSA were quantified by UPLC/ESI-HR-Q-TOFMS, and Org-S were 414 quantified by IR-ICP-MS. 


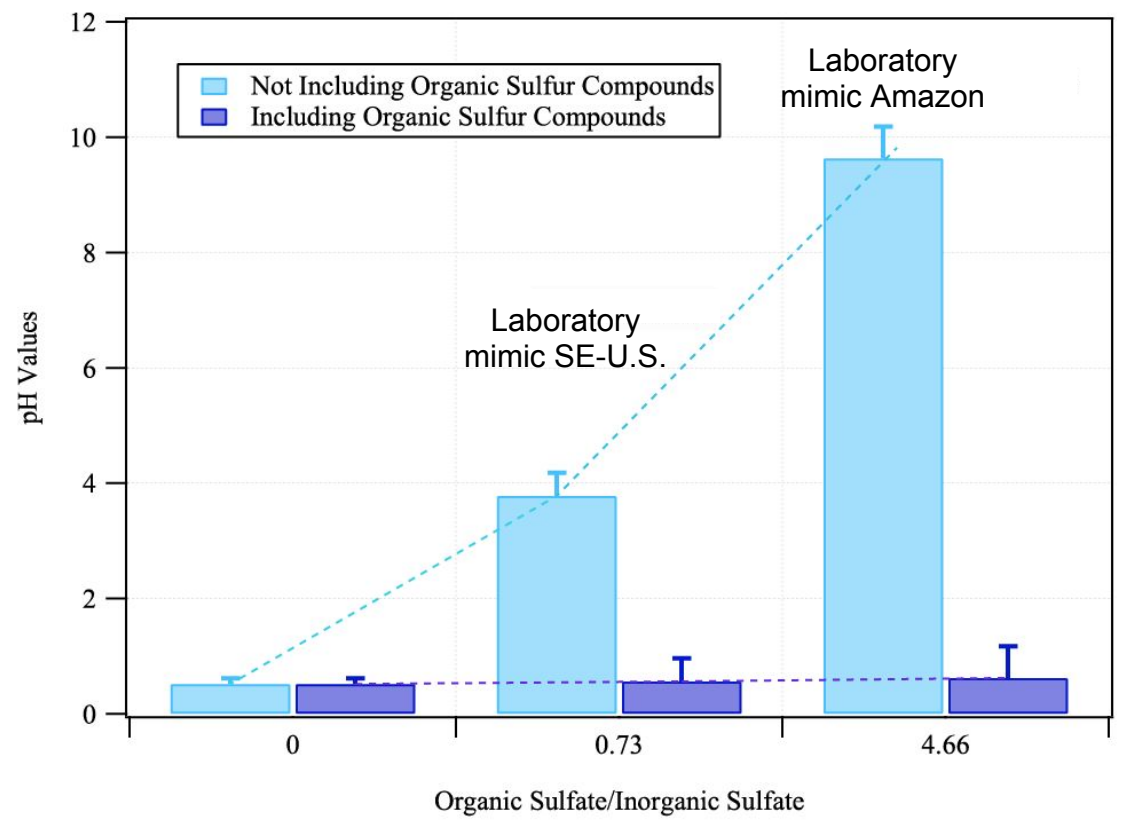

416

417 Figure S6. Comparison of modeled aerosol $\mathrm{pH}$ when considering the acidity of IEPOX-OS vs. not 418 considering IEPOX-OS. The $\mathrm{x}$ axis is the ratio of the total organic sulfur compounds vs. total inorganic 419 sulfur compounds in the aerosol. The light blue bars represent the modelling results of the chamber data 420 without considering IEPOX-OS. The purple bars represent is the modeling results after taking IEPOX-OS 421 into consideration. The center and the right groups show the modelled $\mathrm{pH}$ based on aerosol composition 422 measured at the end of the experiment from the SE-U.S. ratio and the Amazon ratio chamber experiments, 423 respectively. The error bar range is calculated based on the pKa values of IEPOX-OS to be $0-4$. The dashed 424 lines are trendlines. A growth factor of 1.3 and Henry's law constant for $0.0161 \mathrm{~atm} \mathrm{M}^{-1}$ are applied in the 425 model. By varying the $\mathrm{pK}_{\mathrm{a}}$ values of IEPOX-OS, the aerosol acidity changes up to 6 times $(0.8 \mathrm{pH}$ units), 426 suggesting the importance of further research on the role of these SOA constituents in governing the aerosol 427 acidity. 


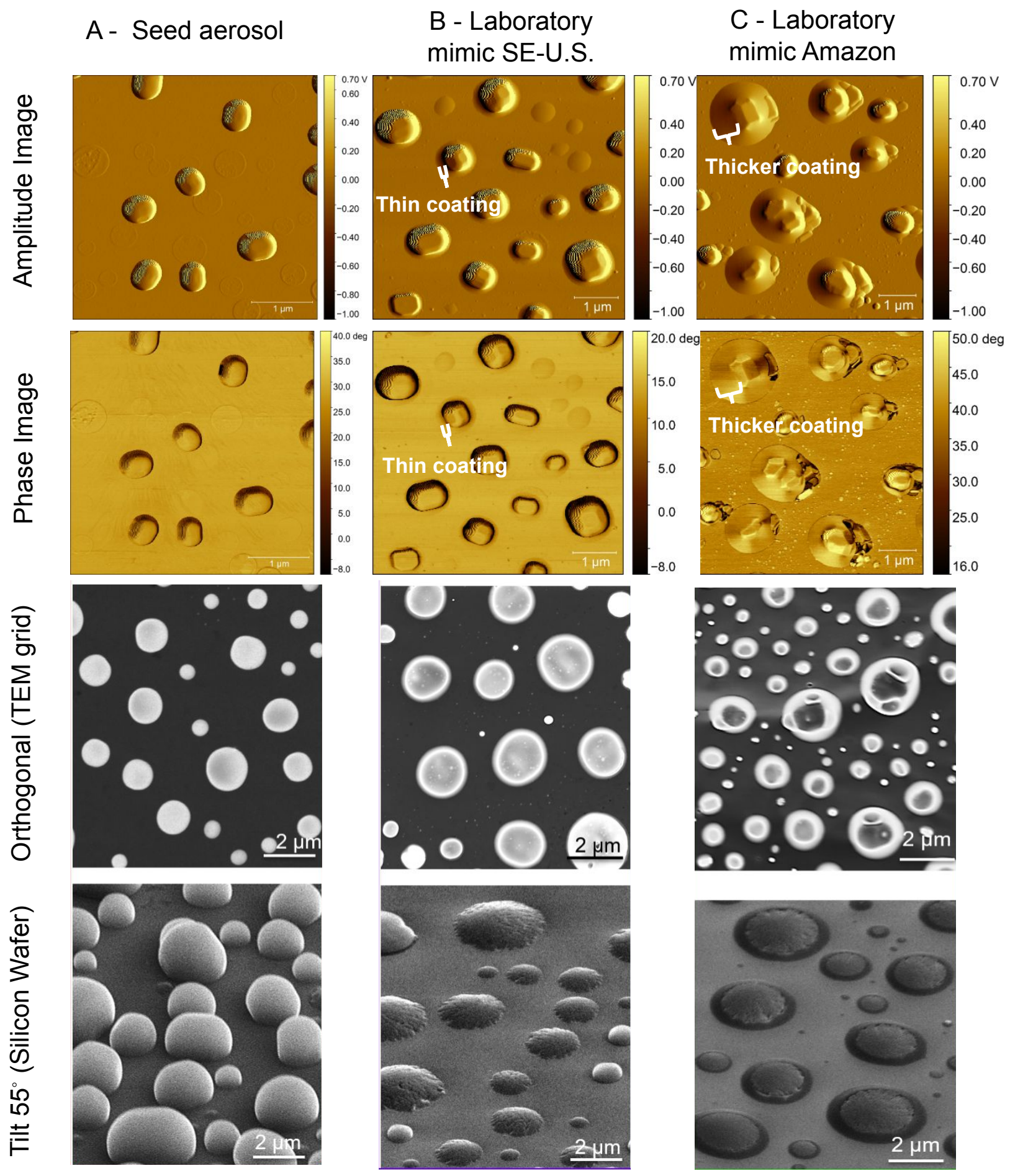

Figure S7. AFM phase and amplitude images for the corresponding height images shown in Figure 3.

430 Scanning electron microscopy images on TEM grids orthogonal to the electron beam (top) and at a 55

431 degree tilt from the beam for (A) seed aerosol, (B) laboratory mimic SE-U.S. conditions and (C) laboratory

432 mimic Amazon conditions (green). SE-U.S. and Amazon are after exposure to IEPOX. 

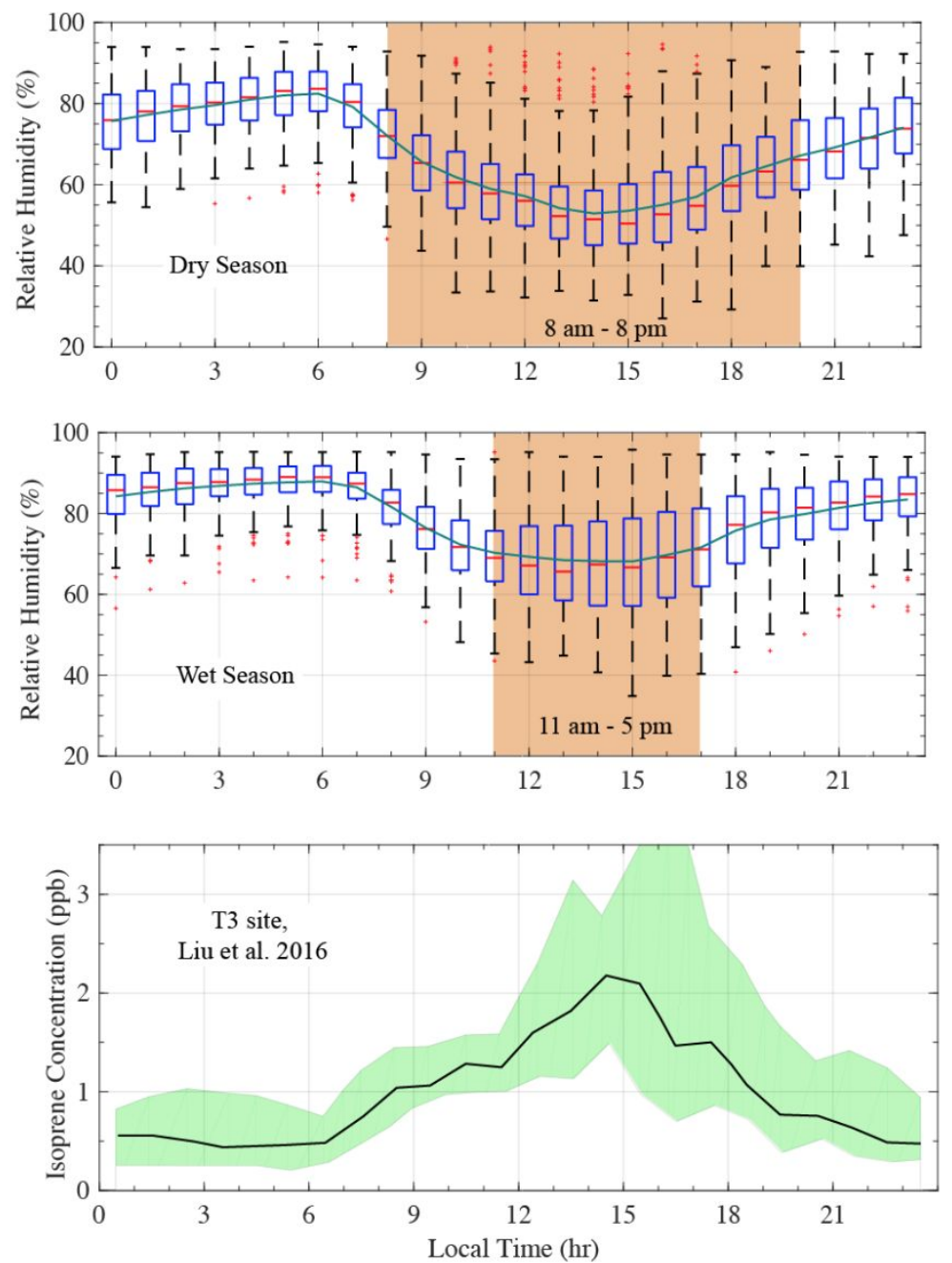

435 Figure S8. The top two panels show the box plots of the hourly relative humidity during dry season (June-

436 September) and wet season (December-March) from 2016-2018 at the Amazon basin (Manaus site). On 437 each box, the central mark indicates the median, and the bottom and top edges of the box indicate the 25th 438 and 75th percentiles, respectively. The whiskers extend to the most extreme data points not considered 439 outliers, and the outliers are shown individually with red plus symbols. Boxplot assigns points as outliers 440 if they are greater than $q_{3}+1.5 \times\left(q_{3}-q_{1}\right)$ or less than $q_{1}-1.5 \times\left(q_{3}-q_{1}\right)$, where $q_{1}$ and $q_{3}$ are the 25 th and 44175 th percentiles of the sample data, respectively. The black line in the bottom panel shows the measured 442 hourly isoprene concentration downwind Manaus in the Amazon basin ${ }^{20}$. For the stations, hourly RH values 443 (calculated from measured temperature and dew point) were retrieved from NOAA's National Climatic 444 Data Center (http://www.ncdc.noaa.gov/). The green lines in the top two panels represent the mean hourly $445 \mathrm{RH}$. The orange-shaded areas represent the periods when the average $\mathrm{RH}<70 \%$. 


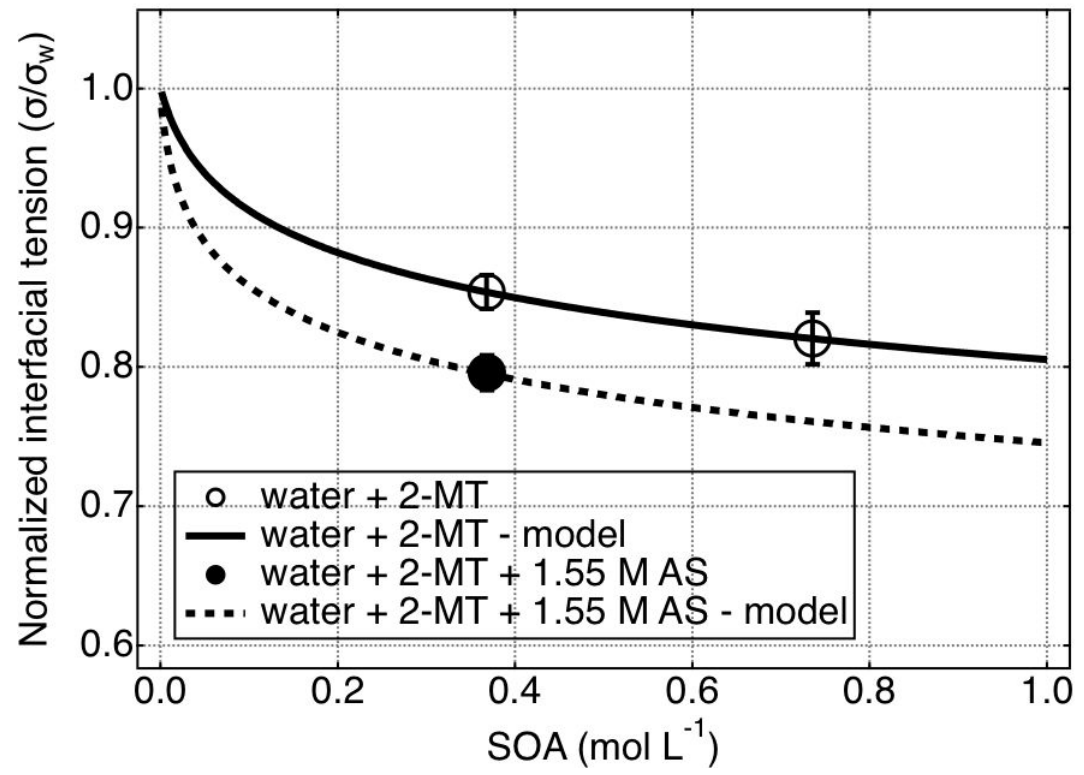

447 Figure S9. Measured and modeled interfacial tensions for 2-methyltetrols (2-MT). 

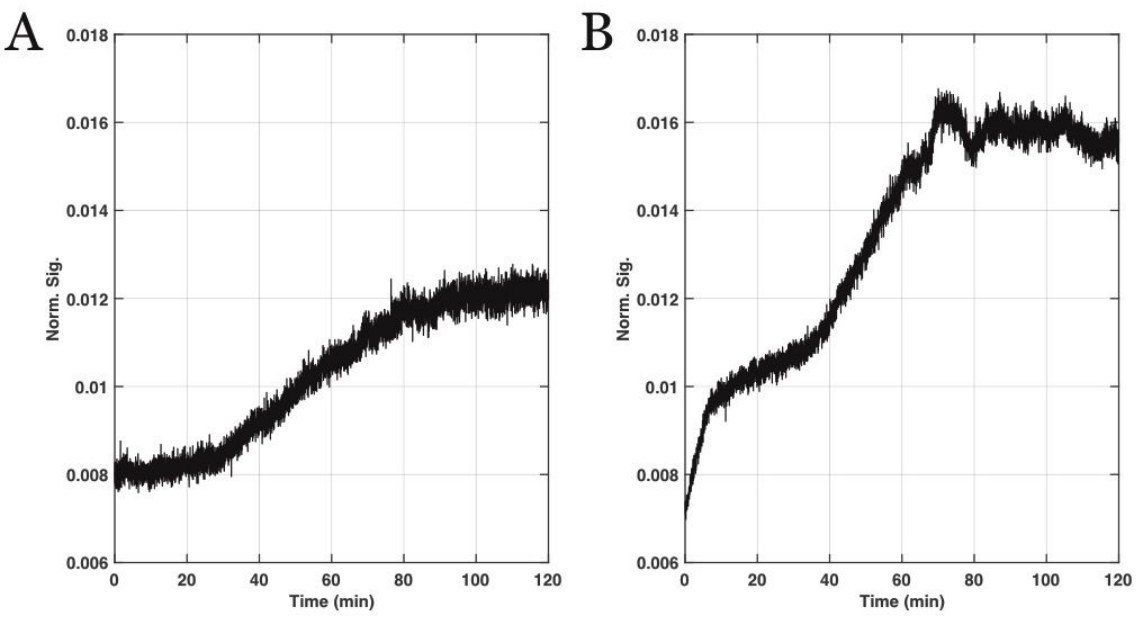

449 Figure S10. Time series of IEPOX signal in aerosol particles normalized by iodide signal measured by a

450 high-resolution time-of-flight chemical ionization mass spectrometer equipped with iodide (I-) reagent ion

451 chemistry (I-HR-TOF-CIMS) during the reactive uptake of IEPOX chamber experiments under 452 atmospheric IEPOX: $\mathrm{SO}_{4}{ }^{2-}$ relevant to (A) SE-U.S. and (B) Amazon, corresponding to experiments shown 453 in Figures $1 \mathrm{~A} \&$ 1B, respectively. Increasing slope of IEPOX signal indicates the injection rate of IEPOX 454 was faster than its reactive and wall losses, a decreasing slope indicates reactive uptake to the particle phase 455 is gradually slowing down as the reaction continues. 
Table S1. Summary of indoor smog chamber conditions used for IEPOX uptake experiments using 458 ammonium bisulfate (ABS) seed aerosols.

\begin{tabular}{|c|c|c|c|c|c|}
\hline No & Description & $\begin{array}{c}\text { Injected } \\
\text { IEPOX (ppb) }\end{array}$ & $\mathrm{SO}_{4}{ }^{2-}\left(\mu \mathrm{g} / \mathrm{m}^{3}\right)$ & IEPOX/SO & RH (\%) \\
\hline 1 & IEPOX + ABS & 48 & 430.2 & 0.5 & 49.8 \\
\hline 2 & IEPOX + ABS & 104 & 658.4 & 0.8 & 47.0 \\
\hline 3 & IEPOX + ABS & 122 & 664.0 & 0.9 & 46.3 \\
\hline 4 & IEPOX + ABS & 172 & 669.6 & 1.3 & 53.2 \\
\hline 5 & IEPOX + ABS & 140 & 437.4 & 1.5 & 52.2 \\
\hline 6 & IEPOX + ABS & 166 & 179.2 & 4.5 & 48.9 \\
\hline 7 & IEPOX + ABS & 218 & 175.8 & 6.0 & 47.7 \\
\hline 8 & IEPOX + ABS & 240 & 111.1 & 10.5 & 48.9 \\
\hline 9 & IEPOX + ABS & 174 & 76.4 & 11.1 & 46.4 \\
\hline 10 & IEPOX + ABS & 176 & 70.7 & 12.1 & 48.0 \\
\hline 11 & IEPOX + ABS & 230 & 65.6 & 17.1 & 50.4 \\
\hline 12 & IEPOX + ABS & 124 & 31.0 & 19.5 & 46.5 \\
\hline 13 & IEPOX + ABS & 174 & 41.1 & 20.7 & 48.8 \\
\hline
\end{tabular}


Table S2. Average and maximum concentrations of the OS identified during the 2013 SOAS campaign.

\begin{tabular}{|c|c|c|c|c|c|}
\hline $\begin{array}{c}\text { Suggested } \\
\text { Formula }\end{array}$ & $\begin{array}{l}{[\mathbf{M}-\mathbf{H}]^{-}} \\
\text {ion }\end{array}$ & $\begin{array}{c}\text { Average } \\
\text { concentration } \\
\left(\mathbf{n g ~ m}^{-3}\right) \\
\end{array}$ & $\begin{array}{c}\text { Max } \\
\text { concentration } \\
\left(\mathrm{ng} \mathrm{m}^{-3}\right) \\
\end{array}$ & $\begin{array}{c}\text { Average } \\
\text { OS/Sum } \\
\text { OS (\%) }\end{array}$ & $\begin{array}{l}\text { Precursor } \\
\text { group }\end{array}$ \\
\hline $\mathrm{CH}_{3} \mathrm{O}_{3} \mathrm{~S}^{-a, b}$ & 94.98 & 39.27 & 167.59 & 10.53 & Dimethylsulfide \\
\hline $\mathrm{CH}_{3} \mathrm{O}_{4} \mathrm{~S}^{-a, c}$ & 110.97 & 3.03 & 20.95 & 0.82 & - \\
\hline $\mathrm{C}_{2} \mathrm{H}_{3} \mathrm{O}_{5} \mathrm{~S}^{-a, c}$ & 138.97 & 0.83 & 2.51 & 0.26 & $\begin{array}{c}\text { Isoprene / } \\
\text { Anthropogenic }\end{array}$ \\
\hline $\mathrm{C}_{3} \mathrm{H}_{5} \mathrm{O}_{5} \mathrm{~S}^{-a, c}$ & 152.98 & 4.95 & 18.22 & 1.34 & $\begin{array}{c}\text { Isoprene / } \\
\text { Anthropogenic }\end{array}$ \\
\hline $\mathrm{C}_{3} \mathrm{H}_{5} \mathrm{O}_{6} \mathrm{~S}^{-a, c}$ & 168.98 & 12.83 & 35.33 & 3.10 & $\begin{array}{c}\text { Isoprene / } \\
\text { Anthropogenic }\end{array}$ \\
\hline $\mathrm{C}_{5} \mathrm{H}_{9} \mathrm{O}_{5} \mathrm{~S}^{-a, d}$ & 181.01 & 0.14 & 2.51 & 0.04 & Isoprene \\
\hline $\mathrm{C}_{4} \mathrm{H}_{7} \mathrm{O}_{6} \mathrm{~S}^{-a, c}$ & 182.99 & 8.60 & 23.51 & 2.30 & Isoprene \\
\hline $\mathrm{C}_{5} \mathrm{H}_{9} \mathrm{O}_{6} \mathrm{~S}^{-a, e}$ & 197.01 & 4.79 & 16.87 & 0.74 & Isoprene \\
\hline $\mathrm{C}_{4} \mathrm{H}_{7} \mathrm{O}_{7} \mathrm{~S}^{-a, d}$ & 198.99 & 10.72 & 43.07 & 2.90 & Isoprene \\
\hline $\mathrm{C}_{5} \mathrm{H}_{11} \mathrm{O}_{6} \mathrm{~S}^{-a, e}$ & 199.02 & 2.78 & 9.04 & 0.73 & Isoprene \\
\hline $\mathrm{C}_{8} \mathrm{H}_{9} \mathrm{O}_{4} \mathrm{~S}^{-a, e}$ & 201.02 & 1.39 & 4.17 & 0.37 & Isoprene \\
\hline $\mathrm{C}_{5} \mathrm{H}_{7} \mathrm{O}_{7} \mathrm{~S}^{-a, e}$ & 210.99 & 7.31 & 27.45 & 1.96 & Isoprene \\
\hline $\mathrm{C}_{5} \mathrm{H}_{9} \mathrm{O}_{7} \mathrm{~S}^{-a, e}$ & 213.00 & 7.84 & 23.99 & 2.10 & Isoprene \\
\hline $\mathrm{C}_{5} \mathrm{H}_{11} \mathrm{O}_{7} \mathrm{~S}^{-a, e}$ & 215.02 & 217.14 & 755.3 & 58.39 & Isoprene \\
\hline $\mathrm{C}_{5} \mathrm{H}_{7} \mathrm{O}_{8} \mathrm{~S}^{-a, e}$ & 226.98 & 4.25 & 14.12 & 1.14 & Isoprene \\
\hline $\mathrm{C}_{6} \mathrm{H}_{11} \mathrm{O}_{7} \mathrm{~S}^{-a, e}$ & 227.02 & 0.43 & 2.94 & 0.11 & Isoprene \\
\hline $\mathrm{C}_{5} \mathrm{H}_{9} \mathrm{O}_{8} \mathrm{~S}^{-a, e}$ & 229.00 & 6.91 & 21.33 & 1.82 & Isoprene \\
\hline $\mathrm{C}_{5} \mathrm{H}_{11} \mathrm{O}_{8} \mathrm{~S}^{-a, e}$ & 231.01 & 0.38 & 3.72 & 0.12 & Isoprene \\
\hline $\mathrm{C}_{7} \mathrm{H}_{11} \mathrm{O}_{7} \mathrm{~S}^{-f, g}$ & 239.02 & 4.20 & 14.22 & 1.29 & Limonene \\
\hline $\mathrm{C}_{10} \mathrm{H}_{17} \mathrm{O}_{5} \mathrm{~S}^{-f, h}$ & 249.08 & 0.93 & 2.56 & 0.26 & Monoterpenes \\
\hline
\end{tabular}




\begin{tabular}{|c|c|c|c|c|c|}
\hline $\begin{array}{c}\text { Suggested } \\
\text { Formula }\end{array}$ & $\begin{array}{l}{[\mathbf{M}-\mathbf{H}]^{-}} \\
\text {ion }\end{array}$ & $\begin{array}{c}\text { Average } \\
\text { concentration } \\
\left(\mathrm{ng} \mathrm{m}^{-3}\right)\end{array}$ & $\begin{array}{c}\text { Max } \\
\text { concentration } \\
\left(\mathrm{ng} \mathrm{m}^{-3}\right) \\
\end{array}$ & $\begin{array}{l}\text { Average } \\
\text { OS/Sum } \\
\text { OS (\%) }\end{array}$ & $\begin{array}{l}\text { Precursor } \\
\text { group }\end{array}$ \\
\hline $\mathrm{C}_{5} \mathrm{H}_{10} \mathrm{NO}_{9} \mathrm{~S}^{-f, g}$ & 260.00 & 16.41 & 124.14 & 4.40 & Isoprene \\
\hline $\mathrm{C}_{9} \mathrm{H}_{15} \mathrm{O}_{7} \mathrm{~S}^{-f, h}$ & 267.05 & 1.39 & 3.36 & 0.37 & $\begin{array}{l}\text { Isoprene / } \\
\text { Limonene }\end{array}$ \\
\hline $\mathrm{C}_{10} \mathrm{H}_{15} \mathrm{O}_{7} \mathrm{~S}^{-f, h}$ & 279.05 & 1.02 & 3.41 & 0.30 & Monoterpenes \\
\hline $\mathrm{C}_{10} \mathrm{H}_{17} \mathrm{O}_{7} \mathrm{~S}^{-f, h}$ & 281.07 & 2.15 & 15.10 & 0.60 & $\alpha$-terpinene \\
\hline $\mathrm{C}_{10} \mathrm{H}_{16} \mathrm{NO}_{7} \mathrm{~S}^{-f, h}$ & 294.06 & 4.24 & 88.69 & 1.17 & Monoterpenes \\
\hline $\mathrm{C}_{9} \mathrm{H}_{14} \mathrm{NO}_{8} \mathrm{~S}^{-f, h}$ & 296.04 & 0.53 & 6.76 & 0.15 & Limonene \\
\hline $\mathrm{C}_{10} \mathrm{H}_{16} \mathrm{NO}_{8} \mathrm{~S}^{-f, h}$ & 310.06 & 12.88 & 96.11 & 3.47 & Monoterpenes \\
\hline $\mathrm{C}_{10} \mathrm{H}_{19} \mathrm{O}_{9} \mathrm{~S}^{-f, h}$ & 315.07 & 0.36 & 1.44 & 0.19 & Isoprene \\
\hline $\mathrm{C}_{10} \mathrm{H}_{14} \mathrm{NO}_{9} \mathrm{~S}^{-f, h}$ & 324.04 & 1.12 & 13.56 & 0.31 & Monoterpenes \\
\hline $\mathrm{C}_{10} \mathrm{H}_{16} \mathrm{NO}_{9} \mathrm{~S}^{-f, h}$ & 326.05 & 1.47 & 15.89 & 0.41 & Monoterpenes \\
\hline $\mathrm{C}_{10} \mathrm{H}_{21} \mathrm{O}_{10} \mathrm{~S}^{-f, g}$ & 333.08 & 0.69 & 3.23 & 0.18 & Isoprene \\
\hline $\mathrm{C}_{10} \mathrm{H}_{16} \mathrm{NO}_{10} \mathrm{~S}^{-f, h}$ & 342.05 & 0.31 & 2.12 & 0.09 & Monoterpenes \\
\hline $\mathrm{C}_{10} \mathrm{H}_{15} \mathrm{~N}_{2} \mathrm{O}_{10} \mathrm{~S}^{-f, h}$ & 355.04 & 0.81 & 18.66 & 0.22 & $\alpha$-pinene \\
\hline $\mathrm{C}_{10} \mathrm{H}_{17} \mathrm{~N}_{2} \mathrm{O}_{11} \mathrm{~S}^{-f, h}$ & 373.06 & 0.34 & 7.17 & 0.10 & Limonene \\
\hline
\end{tabular}

461

462 a OS are eluted within the first 2 minutes; ${ }^{b}$ quantified using methylsulfonic acid; ${ }^{c}$ OS quantified 463 using 2-oxopropyl sulfate; ' OS quantified using 2-methylglyceric acid sulfates; ${ }^{\text {e }}$ OS quantified 464 using 2-methyltetrol sulfates; ${ }^{f}$ OS are eluted during the elution gradient; ${ }^{g}$ OS quantified using 465 propyl sulfate; ${ }^{h}$ OS quantified using 3-pinanol-2-hydrogen sulfate; ${ }^{i}$ OS quantified using octyl 466 sulfate.

467 
468 Table S3. Average and maximum concentrations of the OS identified during the Go-Amazon

469 campaign.

\begin{tabular}{|c|c|c|c|c|c|}
\hline $\begin{array}{l}\text { Suggested } \\
\text { Formula }\end{array}$ & $\begin{array}{l}{[\mathbf{M}-\mathbf{H}]^{-}} \\
\text {ion }\end{array}$ & $\begin{array}{c}\text { Average } \\
\text { concentration } \\
\left(\mathrm{ng} \mathrm{m}^{-3}\right)\end{array}$ & $\begin{array}{c}\text { Max } \\
\text { concentration } \\
\left(\mathrm{ng} \mathrm{m}^{-3}\right)\end{array}$ & $\begin{array}{c}\text { Average } \\
\text { OS/Sum } \\
\text { OS (\%) }\end{array}$ & $\begin{array}{l}\text { Precursor } \\
\text { group }\end{array}$ \\
\hline $\mathrm{C}_{3} \mathrm{H}_{5} \mathrm{O}_{5} \mathrm{~S}^{-a, b}$ & 152.98 & 29.9 & 69.6 & 4.8 & $\begin{array}{c}\text { Isoprene / } \\
\text { Anthropogenic }\end{array}$ \\
\hline $\mathrm{C}_{3} \mathrm{H}_{5} \mathrm{O}_{5} \mathrm{~S}^{-a, b}$ & 154.98 & 25.3 & 47.9 & 4.1 & $\begin{array}{c}\text { Isoprene / } \\
\text { Anthropogenic }\end{array}$ \\
\hline $\mathrm{C}_{3} \mathrm{H}_{5} \mathrm{O}_{6} \mathrm{~S}^{-a, b}$ & 168.98 & 19 & 45.6 & 1.4 & $\begin{array}{c}\text { Isoprene / } \\
\text { Anthropogenic }\end{array}$ \\
\hline $\mathrm{C}_{4} \mathrm{H}_{7} \mathrm{O}_{6} \mathrm{~S}^{-a, b}$ & 182.99 & 29.5 & 71.4 & 3.1 & Isoprene \\
\hline $\mathrm{C}_{5} \mathrm{H}_{11} \mathrm{O}_{6} \mathrm{~S}^{-a, b}$ & 199.02 & 101.0 & 283.4 & 16.3 & Isoprene \\
\hline $\mathrm{C}_{5} \mathrm{H}_{11} \mathrm{O}_{7} \mathrm{~S}^{-a, b}$ & 215.02 & 398.5 & 1450.2 & 64.2 & Isoprene \\
\hline
\end{tabular}

$470 \quad$ OS are eluted within the first 2 minutes; ${ }^{b}$ OS quantified using 2-methyltetrol sulfates.

471 
472 Table S4. Average and maximum concentrations of the OS identified in Manaus.

\begin{tabular}{|c|c|c|c|c|c|}
\hline $\begin{array}{c}\text { Suggested } \\
\text { Formula }\end{array}$ & $\begin{array}{l}{[\mathbf{M}-\mathbf{H}]^{-}} \\
\text {ion }\end{array}$ & $\begin{array}{c}\text { Average } \\
\text { concentration } \\
\left(\mathrm{ng} \mathrm{m}^{-3}\right)\end{array}$ & $\begin{array}{c}\text { Max } \\
\text { concentration } \\
\left(\mathrm{ng} \mathrm{m}^{-3}\right)\end{array}$ & $\begin{array}{l}\text { Average } \\
\text { OS/Sum } \\
\text { OS (\%) }\end{array}$ & $\begin{array}{l}\text { Precursor } \\
\text { group }\end{array}$ \\
\hline $\mathrm{C}_{2} \mathrm{H}_{3} \mathrm{O}_{5} \mathrm{~S}^{-a, c}$ & 138.97 & 19.8 & 25.2 & 1.3 & $\begin{array}{c}\text { Isoprene / } \\
\text { Anthropogenic }\end{array}$ \\
\hline $\mathrm{C}_{3} \mathrm{H}_{5} \mathrm{O}_{5} \mathrm{~S}^{-a, c}$ & 152.98 & 87.4 & 301.1 & 5.8 & $\begin{array}{c}\text { Isoprene / } \\
\text { Anthropogenic }\end{array}$ \\
\hline $\mathrm{C}_{3} \mathrm{H}_{5} \mathrm{O}_{5} \mathrm{~S}^{-a, c}$ & 154.98 & 87.0 & 122.8 & 5.8 & $\begin{array}{c}\text { Isoprene / } \\
\text { Anthropogenic }\end{array}$ \\
\hline $\mathrm{C}_{5} \mathrm{H}_{7} \mathrm{O}_{5} \mathrm{~S}^{-f, g}$ & 179.0 & 4.0 & 11.9 & 0.3 & Cyclohexene \\
\hline $\mathrm{C}_{4} \mathrm{H}_{7} \mathrm{O}_{6} \mathrm{~S}^{-a, c}$ & 182.99 & 47.1 & 120.7 & 3.1 & Isoprene \\
\hline $\mathrm{C}_{6} \mathrm{H}_{11} \mathrm{O}_{5} \mathrm{~S}^{-f, g}$ & 195.03 & 1.5 & 7.0 & 0.1 & $\begin{array}{l}\text { Cyclohexene/ } \\
\text { Pinonaldehyde }\end{array}$ \\
\hline $\mathrm{C}_{5} \mathrm{H}_{9} \mathrm{O}_{6} \mathrm{~S}^{-a, e}$ & 197.01 & 15.6 & 24.5 & 1.0 & Isoprene \\
\hline $\mathrm{C}_{5} \mathrm{H}_{11} \mathrm{O}_{6} \mathrm{~S}^{-a, e}$ & 199.02 & 58.9 & 84.2 & 3.9 & Isoprene \\
\hline $\mathrm{C}_{5} \mathrm{H}_{7} \mathrm{O}_{7} \mathrm{~S}^{-a, e}$ & 210.99 & 9.7 & 13.8 & 0.6 & Isoprene \\
\hline $\mathrm{C}_{5} \mathrm{H}_{9} \mathrm{O}_{7} \mathrm{~S}^{-a, e}$ & 213.00 & 100.5 & 137.8 & 6.7 & Isoprene \\
\hline $\mathrm{C}_{5} \mathrm{H}_{11} \mathrm{O}_{7} \mathrm{~S}^{-a, e}$ & 215.02 & 823.3 & 1159.7 & 55.0 & Isoprene \\
\hline $\mathrm{C}_{7} \mathrm{H}_{11} \mathrm{O}_{5} \mathrm{~S}^{-f, g}$ & 223.02 & 6.5 & 11.2 & 0.4 & $\alpha$-pinene \\
\hline $\mathrm{C}_{5} \mathrm{H}_{9} \mathrm{O}_{8} \mathrm{~S}^{-a, e}$ & 229.00 & 20.1 & 27.1 & 1.3 & Isoprene \\
\hline $\mathrm{C}_{5} \mathrm{H}_{11} \mathrm{O}_{8} \mathrm{~S}^{-a, e}$ & 231.01 & 7.0 & 9.7 & 0.5 & Isoprene \\
\hline $\mathrm{C}_{7} \mathrm{H}_{11} \mathrm{O}_{7} \mathrm{~S}^{-f, g}$ & 237.04 & 6.1 & 8.3 & 0.4 & $\alpha$-pinene \\
\hline $\mathrm{C}_{7} \mathrm{H}_{11} \mathrm{O}_{7} \mathrm{~S}^{-f, g}$ & 239.02 & 14.5 & 19.2 & 1.0 & Limonene \\
\hline $\mathrm{C}_{10} \mathrm{H}_{17} \mathrm{O}_{5} \mathrm{~S}^{-f, h}$ & 249.04 & 24.1 & 69.4 & 1.6 & Monoterpenes \\
\hline $\mathrm{C}_{10} \mathrm{H}_{19} \mathrm{O}_{5} \mathrm{~S}^{-f, h}$ & 251.09 & 7.6 & 19.7 & 0.5 & Cyclodecane \\
\hline $\mathrm{C}_{8} \mathrm{H}_{13} \mathrm{O}_{7} \mathrm{~S}^{-f, g}$ & 253.03 & 3.4 & 4.7 & 0.2 & Isoprene \\
\hline
\end{tabular}




\begin{tabular}{|c|c|c|c|c|c|}
\hline $\begin{array}{c}\text { Suggested } \\
\text { Formula }\end{array}$ & $\begin{array}{l}{[\mathbf{M}-\mathbf{H}]^{-}} \\
\text {ion }\end{array}$ & $\begin{array}{c}\text { Average } \\
\text { concentration } \\
\left(\mathbf{n g ~ m}^{-3}\right)\end{array}$ & $\begin{array}{c}\text { Max } \\
\text { concentration } \\
\left(\mathbf{n g ~ m}^{-3}\right)\end{array}$ & $\begin{array}{c}\text { Average } \\
\text { OS/Sum } \\
\text { OS (\%) } \\
\end{array}$ & $\begin{array}{c}\text { Precursor } \\
\text { group }\end{array}$ \\
\hline $\mathrm{C}_{5} \mathrm{H}_{10} \mathrm{NO}_{7} \mathrm{~S}^{-f, g}$ & 260.00 & 48.7 & 19.2 & 0.6 & Isoprene \\
\hline $\mathrm{C}_{10} \mathrm{H}_{15} \mathrm{O}_{7} \mathrm{~S}^{-f, h}$ & 279.05 & 9.6 & 13.9 & 0.6 & Monoterpene \\
\hline $\mathrm{C}_{12} \mathrm{H}_{23} \mathrm{O}_{5} \mathrm{~S}^{-f, i}$ & 279.12 & 6.3 & 10.9 & 0.4 & Dodecane \\
\hline $\mathrm{C}_{10} \mathrm{H}_{17} \mathrm{O}_{7} \mathrm{~S}^{-f, h}$ & 281.06 & 13.8 & 22.7 & 0.9 & Monoterpene \\
\hline $\mathrm{C}_{10} \mathrm{H}_{16} \mathrm{NO}_{7} \mathrm{~S}^{-f, h}$ & 295.06 & 39.0 & 56.0 & 2.6 & Monoterpene \\
\hline $\mathrm{C}_{9} \mathrm{H}_{14} \mathrm{NO}_{8} \mathrm{~S}^{-f, h}$ & 296.04 & 2.7 & 5.9 & 0.2 & Limonene \\
\hline $\mathrm{C}_{10} \mathrm{H}_{19} \mathrm{O}_{10} \mathrm{~S}^{-f, h}$ & 331.06 & 16.5 & 26.7 & 1.1 & Isoprene \\
\hline $\mathrm{C}_{10} \mathrm{H}_{21} \mathrm{O}_{10} \mathrm{~S}^{-f, h}$ & 333.08 & 50.1 & 90.6 & 3.3 & Isoprene \\
\hline $\mathrm{C}_{20} \mathrm{H}_{39} \mathrm{O}_{15} \mathrm{~S}^{-f, g}$ & 451.14 & 1.8 & 5.5 & 0.1 & Isoprene \\
\hline
\end{tabular}

$473 \quad \bar{a}$ OS are eluted within the first 2 minutes; ${ }^{b}$ quantified using methylsulfonic acid; ${ }^{c}$ OS quantified

474 using 2-oxopropyl sulfate; d OS quantified using 2-methylglyceric acid sulfates; ${ }^{e}$ OS quantified 475 using 2-methyltetrol sulfates; ${ }^{f}$ OS are eluted during the elution gradient; $g$ OS quantified using 476 propyl sulfate; ${ }^{h}$ OS quantified using 3-pinanol-2-hydrogen sulfate; ${ }^{i}$ OS quantified using octyl 477 sulfate. 
479 Table S5. Calibration factors and retention times of the OS standards.

\begin{tabular}{|c|c|c|c|c|c|}
\hline Formula & Name & {$[\mathbf{M}-\mathbf{H}]^{-}$} & $\begin{array}{c}\text { Calibration } \\
\text { factor }\end{array}$ & $r^{2}$ & $\begin{array}{c}\text { Retention } \\
\text { time(s) (min) }\end{array}$ \\
\hline $\mathrm{C}_{4} \mathrm{H}_{7} \mathrm{O}_{7} \mathrm{~S}^{-}$ & $\begin{array}{l}\text { 2-methylglyceric acid } \\
\text { sulfate }\end{array}$ & 198.99 & $1.01 \times 10^{6}$ & 0.99 & 1.8 \\
\hline $\mathrm{C}_{5} \mathrm{H}_{11} \mathrm{O}_{7} \mathrm{~S}^{-}$ & 2-methyltetrol sulfate & 215.02 & $1.02 \times 10^{6}$ & 0.99 & $1.1 / 1.8$ \\
\hline $\mathrm{C}_{2} \mathrm{H}_{3} \mathrm{O}_{6} \mathrm{~S}^{-}$ & Glycolic acid sulfate & 154.96 & $1.09 \times 10^{6}$ & 0.98 & 1.8 \\
\hline $\mathrm{C}_{3} \mathrm{H}_{5} \mathrm{O}_{5} \mathrm{~S}^{-}$ & $\begin{array}{l}\text { 2-oxopropyl } \\
\text { sulfate }\end{array}$ & 152.98 & $1.16 \times 10^{6}$ & 0.99 & 1.8 \\
\hline $\mathrm{C}_{3} \mathrm{H}_{7} \mathrm{O}_{4} \mathrm{~S}^{-}$ & Propyl sulfate & 139.00 & $3.68 \times 10^{6}$ & 0.99 & 3.5 \\
\hline $\mathrm{C}_{9} \mathrm{H}_{13} \mathrm{O}_{6} \mathrm{~S}^{-}$ & $\begin{array}{l}\text { 3-pinanol-2-hydrogen } \\
\text { sulfate }\end{array}$ & 249.04 & $3.01 \times 10^{6}$ & 0.90 & 8.6 \\
\hline $\mathrm{C}_{8} \mathrm{H}_{17} \mathrm{O}_{4} \mathrm{~S}^{-}$ & Octyl sulfate & 209.08 & $1.10 \times 10^{8}$ & 0.99 & 11.5 \\
\hline
\end{tabular}

480 
482 Table S6. The fitting parameters for the glass transition calculation at dry condition.

\begin{tabular}{cccccc}
\hline $\boldsymbol{n}_{\boldsymbol{C}}^{\mathbf{0}}$ & $\boldsymbol{b}_{\boldsymbol{C}}$ & $\boldsymbol{b}_{\boldsymbol{H}}$ & $\boldsymbol{b}_{\boldsymbol{C H}}$ & $\boldsymbol{b}_{\boldsymbol{O}}\left(\boldsymbol{b}_{\boldsymbol{S}}\right)$ & $\boldsymbol{b}_{\boldsymbol{C o}}$ \\
\hline 12.13 & 10.95 & -41.82 & 21.61 & 118.96 & -24.38 \\
\hline
\end{tabular}

Table S7. Parameters Used for the Viscosity Calculation of IEPOX-derived OS. Values in the parathesis 485 represent the upper and lower bound values.

\begin{tabular}{ccccc}
\hline Compound & $\begin{array}{c}\text { Glass Transition } \\
\text { Temperature of } \\
\text { Dry SOA (Tg,org) } \\
(\mathbf{K})\end{array}$ & $\begin{array}{c}\text { Hygroscopicity } \\
(\boldsymbol{k})\end{array}$ & $\begin{array}{c}\text { Fragility } \\
(\mathbf{D})\end{array}$ & $\begin{array}{c}\text { The Gordon- } \\
\text { Taylor } \\
\text { Constant }\left(\boldsymbol{k}_{\mathbf{G T}}\right):\end{array}$ \\
\hline $\begin{array}{c}\text { a-Pinene SOA } \\
\text { 2-Methyltetrol } \\
\text { Sulfate }\end{array}$ & $278.5(268.5-300)$ & $0.1(0.1)$ & $10(10-20)$ & $2.5(2.5-3.0)$ \\
$\begin{array}{c}\text { IEPOX-derived } \\
\text { OS Mixture }\end{array}$ & $313(303-330)$ & $0.12(0.1-0.15)$ & $13(10-20)$ & $2.5(2.5-3.0)$ \\
\hline
\end{tabular}




\section{References Supplementary Materials.}

(1) Budisulistiorini, S. H.; Li, X.; Bairai, S. T.; Renfro, J.; Liu, Y.; Liu, Y. J.; McKinney, K. A.; Martin, S. T.; McNeill, V. F.; Pye, H. O. T.; Nenes, A.; Neff, M. E.; Stone, E. A.; Mueller, S.; Knote, C.; Shaw, S. L.; Zhang, Z.; Gold, A.; Surratt, J. D. Examining the Effects of Anthropogenic Emissions on Isoprene-Derived Secondary Organic Aerosol Formation during the 2013 Southern Oxidant and Aerosol Study (SOAS) at the Look Rock, Tennessee Ground Site. Atmospheric Chemistry and Physics 2015, 15 (15), 8871-8888. https://doi.org/10.5194/acp-15-8871-2015.

(2) Martin, S. T.; Artaxo, P.; Machado, L. A. T.; Manzi, A. O.; Souza, R. A. F.; Schumacher, C.; Wang, J.; Andreae, M. O.; Barbosa, H. M. J.; Fan, J.; Fish, G.; Goldstein, A. H.; Guenther, A.; Jimenez, J. L., Pöschl, U.; Silva Dias, M. A.; Smith, J. N.; Wendisch M. Introduction: Observations and Modeling of the Green Ocean Amazon (GoAmazon2014/5). Atmospheric Chemistry and Physics 2016, 16 (8), 4785-4797. https://doi.org/10.5194/acp-16-4785-2016.

(3) Liu, P.; Li, Y. J.; Wang, Y.; Gilles, M. K.; Zaveri, R. A.; Bertram, A. K.; Martin, S. T. Lability of Secondary Organic Particulate Matter. Proceedings of the National Academy of Sciences 2016, 113 (45), 12643-12648. https://doi.org/10.1073/pnas.1603138113.

(4) Lin, Y.-H.; Budisulistiorini, S. H.; Chu, K.; Siejack, R. A.; Zhang, H.; Riva, M.; Zhang, Z.; Gold, A.; Kautzman, K. E.; Surratt, J. D. Light-Absorbing Oligomer Formation in Secondary Organic Aerosol from Reactive Uptake of Isoprene Epoxydiols. Environmental Science \& Technology 2014, 48 (20), 12012-12021. https://doi.org/10.1021/es503142b.

(5) Riva, M.; Budisulistiorini, S. H.; Chen, Y.; Zhang, Z.; D’Ambro, E. L.; Zhang, X.; Gold, A.; Turpin, B. J.; Thornton, J. A.; Canagaratna, M. R.; Surratt, J. D. Chemical Characterization of Secondary Organic Aerosol from Oxidation of Isoprene Hydroxyhydroperoxides. Environmental Science \& Technology 2016, 50 (18), 9889-9899. https://doi.org/10.1021/acs.est.6b02511.

(6) Rattanavaraha, W.; Chu, K.; Budisulistiorini, S. H.; Riva, M.; Lin, Y.-H.; Edgerton, E. S.; Baumann, K.; Shaw, S. L.; Guo, H.; King, L.; Weber, R. J.; Neff, M. E.; Stone, E. A.; Offenberg, J. H.; Zhang, Z.; Gold, A.; Surratt, J. D. Assessing the Impact of Anthropogenic Pollution on Isoprene-Derived Secondary Organic Aerosol Formation in $\mathrm{PM}_{2.5}$ Collected from the Birmingham, Alabama, Ground Site during the 2013 Southern Oxidant and Aerosol Study. Atmospheric Chemistry and Physics 2016, 16 (8), 4897-4914. https://doi.org/10.5194/acp-164897-2016.

(7) Riva, M.; Budisulistiorini, S. H.; Zhang, Z.; Gold, A.; Surratt, J. D. Chemical Characterization of Secondary Organic Aerosol Constituents from Isoprene Ozonolysis in the Presence of Acidic Aerosol. Atmospheric Environment https://doi.org/10.1016/j.atmosenv.2015.06.027.

(8) von Glasow, R.; Crutzen, P. J. Model Study of Multiphase DMS Oxidation with a Focus on Halogens. Atmospheric Chemistry and Physics 2004, 4 (3), 589-608. https://doi.org/10.5194/acp4-589-2004.

(9) Hettiyadura, A. P. S.; Jayarathne, T.; Baumann, K.; Goldstein, A. H.; de Gouw, J. A.; Koss, A.; Keutsch, F. N.; Skog, K.; Stone, E. A. Qualitative and Quantitative Analysis of Atmospheric Organosulfates in Centreville, Alabama. Atmospheric Chemistry and Physics 2017, 17 (2), 13431359. https://doi.org/10.5194/acp-17-1343-2017.

(10) Schwier, A. N.; Viglione, G. A.; Li, Z.; Faye McNeill, V. Modeling the Surface Tension of Complex, Reactive Organic-Inorganic Mixtures. Atmos. Chem. Phys. 2013, 13 (21), 1072110732. https://doi.org/10.5194/acp-13-10721-2013.

(11) Toivola, M.; Prisle, N. L.; Elm, J.; Waxman, E. M.; Volkamer, R.; Kurtén, T. Can 
COSMOTherm Predict a Salting in Effect? The Journal of Physical Chemistry A 2017, 121 (33), 6288-6295. https://doi.org/10.1021/acs.jpca.7b04847.

(12) Gaston, C. J.; Riedel, T. P.; Zhang, Z.; Gold, A.; Surratt, J. D.; Thornton, J. A. Reactive Uptake of an Isoprene-Derived Epoxydiol to Submicron Aerosol Particles. Environmental Science \& Technology 2014, 48 (19), 11178-11186. https://doi.org/10.1021/es5034266.

(13) Zhang, Y.; Chen, Y.; Lambe, A. T.; Olson, N. E.; Lei, Z.; Craig, R. L.; Zhang, Z.; Gold, A.; Onasch, T. B.; Jayne, J. T.; Worsnop, D. R.; Gaston, C. J.; Thornton, J. A.; Vizuete, W.; Ault, A. P.; Surratt, J. D. Effect of the Aerosol-Phase State on Secondary Organic Aerosol Formation from the Reactive Uptake of Isoprene-Derived Epoxydiols (IEPOX). Environmental Science \& Technology Letters 2018, 5 (3), 167-174. https://doi.org/10.1021/acs.estlett.8b00044.

(14) Riedel, T. P.; Lin, Y.-H.; Budisulistiorini, S. H.; Gaston, C. J.; Thornton, J. A.; Zhang, Z.; Vizuete, W.; Gold, A.; Surratt, J. D. Heterogeneous Reactions of Isoprene-Derived Epoxides: Reaction Probabilities and Molar Secondary Organic Aerosol Yield Estimates. Environmental Science \& Technology Letters 2015, 2 (2), 38-42. https://doi.org/10.1021/ez500406f.

(15) DeRieux, W.-S. W.; Li, Y.; Lin, P.; Laskin, J.; Laskin, A.; Bertram, A. K.; Nizkorodov, S. A.; Shiraiwa, M. Predicting the Glass Transition Temperature and Viscosity of Secondary Organic Material Using Molecular Composition. Atmospheric Chemistry and Physics 2018, 18 (9), 63316351. https://doi.org/10.5194/acp-18-6331-2018.

(16) Zobrist, B.; Marcolli, C.; Pedernera, D. A.; Koop, T. Do Atmospheric Aerosols Form Glasses? Atmospheric Chemistry and Physics 2008, 8 (17), 5221-5244. https://doi.org/10.5194/acp-8-5221-2008.

(17) Koop, T.; Bookhold, J.; Shiraiwa, M.; Pöschl, U. Glass Transition and Phase State of Organic Compounds: Dependency on Molecular Properties and Implications for Secondary Organic Aerosols in the Atmosphere. Physical Chemistry Chemical Physics 2011, 13 (43), 19238. https://doi.org/10.1039/c1cp22617g.

(18) Dette, H. P.; Koop, T. Glass Formation Processes in Mixed Inorganic/Organic Aerosol Particles. The Journal of Physical Chemistry A 2015, 119 (19), 4552-4561. https://doi.org/10.1021/jp5106967.

(19) Petters, M. D.; Kreidenweis, S. M. A Single Parameter Representation of Hygroscopic Growth and Cloud Condensation Nucleus Activity. Atmospheric Chemistry and Physics 2007, 7 (8), 1961-1971. https://doi.org/10.5194/acp-7-1961-2007.

(20) Liu, Y.; Brito, J.; Dorris, M. R.; Rivera-Rios, J. C.; Seco, R.; Bates, K. H.; Artaxo, P.; Duvoisin, S.; Keutsch, F. N.; Kim, S.; et al. Isoprene Photochemistry over the Amazon Rainforest. Proceedings of the National Academy of Sciences 2016, 113 (22), 6125-6130. https://doi.org/10.1073/pnas.1524136113. 